\title{
O Stock Flores: Exemplo de magmatismo granítico tipo-A no Domínio Rio Piranhas-Seridó, NE da Província Borborema
}

\author{
Viviane Oliveira de SOUZA ${ }^{1}$, Antônio Carlos GALINDO ${ }^{1,2}$ \& Fernando César ALVES DA SILVA ${ }^{1,2}$
}

1 Programa de Pós-Graduação em Geodinâmica e Geofísica, Universidade Federal do Rio Grande do Norte. Caixa Postal 1.596, CEP 59.078- 970, Natal, RN, Brasil (vivianegeologa@gmail.com).

2 Departamento de Geologia, Universidade Federal do Rio Grande do Norte. Caixa Postal 1.596, CEP 59.078-970, Natal, RN, Brasil (galindo@geologia.ufrn.br, fernando@geologia.ufrn.br).

Recebido em 05/2016. Aceito para publicação em 07/2017.

Versão online publicada em 21/10/2017 (www.pesquisasemgeociencias.ufrgs.br)

\begin{abstract}
Resumo - O Stock granítico Flores intrude gnaisses paleoproterozoicos, relacionados ao Complexo Caicó, no Domínio Rio Piranha-Seridó, porção setentrional da Província Borborema, NE do Brasil. Este trabalho tem como objetivo a caracterização petrológica e geoquímica de seu monzogranitos. o Stock Flores compreende duas fácies petrográficas de monzogranitos equigranulares, leucocráticos: i) monzogranitos rosados de granulação media; e ii) monzogranitos cinza rosados de granulação fina. Localmente ocorrem no Fácies Tipo II, enclaves máficos exibindo feições de coexistência de magmas (mixing e mingling), e schlieren elipsoidais, interpretados como estruturas formadas por convecção magmática. Biotita é o máfico principal; titanita, allanita, apatita, zircão e opacos ocorrem como minerais acessórios; fluorita, clorita e saussurita ocorrem como minerais tardios relacionados a fluídos em estágio subsolidus. As análises geoquímicas evidenciam a natureza evo-

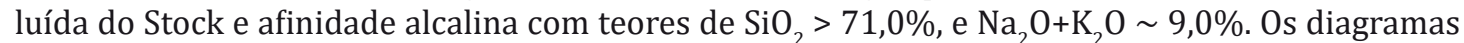
discriminantes de ambiente tectônico demonstram a tipologia de granito Tipo-A. Tais dados são coerentes com a idade U-Pb 553 \pm 4 Ma encontrada para o Stock, o colocando dentro do contexto tardi- a pós-tectônico em relação à Orogênese Brasiliana/Pan-Africana na Província Borborema. Palavras-chave: Granito alcalino, Tardi a Pós-tectônico, Província Borborema.
\end{abstract}

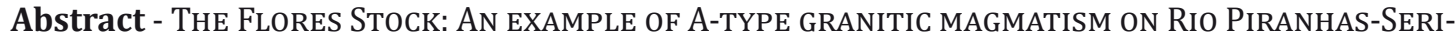
Dó Domain, NE Borborema Province. The Flores granitic stock intrudes paleoproterozoic gneissic related to Caicó Complex, in Rio Piranhas-Seridó Domain, North part of the Borborema Province, NE Brazil. This work focused on the petrological and geochemical characterization of its monzogranites. The Flores Stock comprises equigranular, leucocratic monzogranites, which are divide in two petrografic facies: i) medium grained, pink monzogranites; and ii) fine grained, gray to pink monzogranites. Locally we can find in this type dioritic enclaves displaying magmas coexistence features (mixing and migling), and ellipsoidal schlieren formed by magmatic convection. Mineralogically, the Stock is constitued by biotite as its main mafic; titanite, allanite, apatite, zircon, opaque, and as late minerals, fluorite, chlorite and saussurite, these late ones are interpreted as related to fluids in subsolidus stage. The studied monzogranites show high $\mathrm{SiO}_{2}$ contents $(>71 \% \mathrm{wt} \%)$ and alkaline affinity with $\mathrm{Na}_{2} \mathrm{O}+\mathrm{K}_{2} \mathrm{O} \sim 9,0 \%$. Tectonic discriminant diagrams of tectonic environment suggest a typology of A-type granite related to a post-collisional environment, which is corroborated by U-Pb zircon crystallization age of $553 \pm 4 \mathrm{Ma}$. Thus, the Flores Stock is interpreted as emplaced in a late to post-tectonic stage of the Brasiliana / Pan-African Orogeny in the Borborema Province
\end{abstract} Keywords: Alkaline granite, Late to Post-tectonic, Borborema Province. 


\section{Introdução}

Durante a orogênese Brasiliana/Panafricana, a Província Borborema (PB) foi afetada pelo desenvolvimento de várias zonas de cisalhamento associadas a um intenso tectonismo, metamorfismo de alto grau e expressivo magmatismo plutônico.

O Domínio Rio Piranhas-Seridó, nordeste da Província Borborema (Almeida et al., 1981), é marcado por intenso magmatismo granítico de idade ediacarana a cambriana, relacionado à orogênese Brasiliana/Panafricana. As rochas graníticas resultantes desse magmatismo constituem um importante registro da evolução magmática e tectônica da região permitindo traçar a história evolutiva desses magmas, bem como da província geológica em que ocorrem. Essas rochas graníticas ocorrem com diferentes composições mineralógicas, assinaturas geoquímicas, e dimensões que vão desde batólitos à stocks (Nascimento et al., 2008, 2015). O Stock Flores, objeto deste estudo, insere-se neste contexto.

A caracterização geoquímica, associada à petrografia e dados de campo, tem sido utilizada para suportar interpretações genéticas e evoluções de magmas graníticos e indicar prováveis ambientes tectônicos onde se deu sua colocação.

Este trabalho tem como objetivos a reavaliação/reclassificação do Stock Flores dentro das suítes plutônicas proposta por Nascimento et al. (2008, 2015) bem como a caracterização geológica, petrográfica e geoquímica do Stock, de forma a permitir interpretações petrogenéticas que contribuam para a evolução e compreensão dos conhecimentos do plutonismo tardi a pós-orogênese Brasiliana/Panafricana na porção nordeste da Província Borborema.

\section{2 Área, materiais e métodos}

\subsection{Geologia Regional}

A Província Borborema é uma unidade geotectônica localizada na porção nordeste do Brasil, fortemente afetada pela Orogênese Brasiliana, no final do Neoproterozoico (Almeida et al., 1977). Possui um embasamento arqueano a paleoproterozoico, sequências supracrustais dobradas e numerosos corpos plutônicos neoproterozoicos controlados por zonas de cisalhamento. Vários pesquisadores dedicaram-se a subdivisões da Província Borborema em subprovíncias, subdomínios ou domínios tectônicos distintos, delimita- dos por falhas ou zonas de cisalhamento (Brito Neves et al., 1995; Van Schmus et al., 1995; Santos, 1996, 1999; Santos \& Medeiros, 1999; Santos et al., 2000). Delgado et al. (2003) subdividem a província em três subprovíncias: a Subprovíncia Meridional, limitada pelo lineamento Pernambuco a norte e pelo Cráton do São Francisco a sul; a Subprovíncia da Zona Transversal, limitada a norte e a sul respectivamente pelos lineamentos Patos e Pernambuco; e a Subprovíncia Setentrional posicionada a norte do lineamento Patos.

Na Subprovíncia Setentrional são caracterizados vários terrenos ou domínios geológicos separados por extensas e expressivas zonas de cisalhamento transcorrentes de cinemática dextral de direção NNE-SSW, a exemplo da Zona de Cisalhamento Portalegre (ZCPa) e a Picuí João Câmara no estado do Rio Grande do Norte, sendo reconhecidas como importantes marcadores na divisão de domínios geológicos, delimitando os domínios Jaguaribeano, Rio Piranhas-Seridó e São José do Campestre (Fig. 1).

O Domínio Rio Piranhas-Seridó, no qual situa-se o Stock Flores, engloba várias associações litológicas de idades precambrianas: Complexo Caicó, constituindo o embasamento da área, composto por ortognaisses equigranulares ou augen, anfibolitos, e rochas metavulcânicas e metassedimentares (Jardim de Sá, 1994); Suíte Poço da Cruz, descrita originalmente como granitóides do tipo G2 por Jardim de Sá et al. (1981), composta, principalmente, por augen gnaisses com porfiroclastos de feldspato; e o Grupo Seridó. (Jardim de Sá \& Salim, 1980; Jardim de Sá, 1984) o qual é composto, da base para o topo, pelas formações Jucurutu, Equador e Seridó.

Diversos corpos magmáticos de idade neoproterozoicas (dominantemente ediacaranos) intrudem os litotipos supracitados, ocorrendo com características petrográficas, geoquímicas e geocronológicas distintas. Vários pesquisadores se dedicaram à classificação dessas rochas usando desde parâmetros tectônicos (Almeida et al., 1967; Brito Neves \& Pessoa, 1974; Santos \& Melo, 1978), estruturais (Jardim de Sá et al., 1981) e geoquímicos (Sial, 1987; Galindo et al., 1997a, 1997b; Hollanda, 1998; Nascimento et al., 2000, 2008, 2015). Nascimento et al. (2015) identificaram nos domínios Rio Piranhas-Seridó e São José do Campestre seis suítes magmáticas (Fig. 1) denominadas de Shoshonítica (Shos), Calcioalcalina de alto $\mathrm{K}$ Porfirítica (CalcKP), Calcioalcalina de alto K Equigranular (CalcKEq), Calcioalcalina (CalcAlc), Alcalina (Alc) e Alcalina Charnoquítica (AlcCh). 


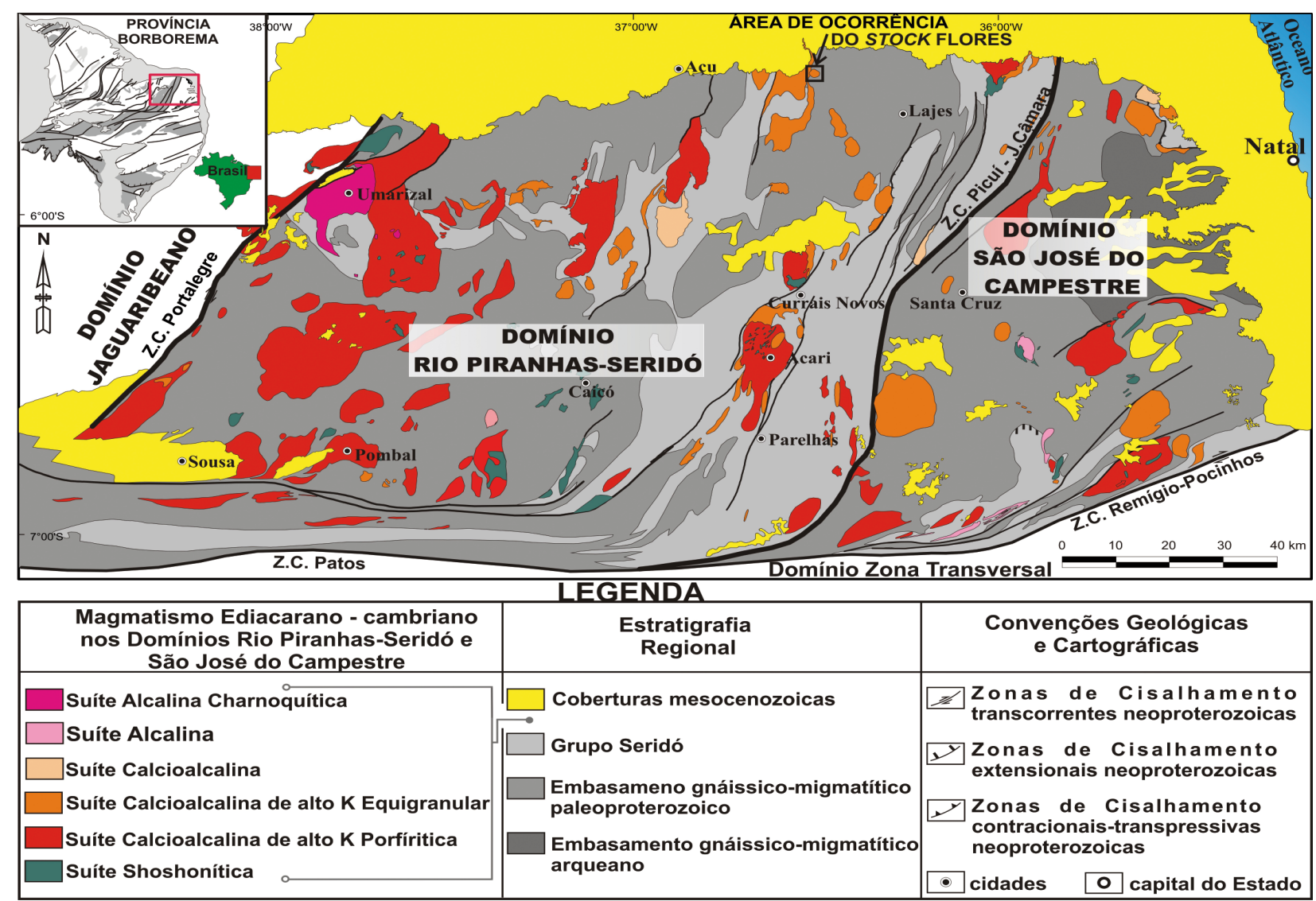

Figura 1. Arcabouço geológico de parte da porção setentrional da Província Borborema com destaque para os domínios Rio Piranhas- Seridó e São José do Campestre, com ênfase no magmatismo Ediacarano a Cambriano (Modificado de Nascimento et al., 2015).

Figure 1. Geological framework of part of the septentrional portion of the Borborema Province highlighting Rio Piranhas- Seridó Domain and São José do Campestre Domain, with emphasis on the Ediacaran to Cambrian magmatism (Modified Nascimento et al., 2015).

\subsection{Geologia do Stock Flores}

0 granito Flores é um stock de aproximadamente $8 \mathrm{~km}^{2}$ de área aflorante, exibindo geometria subcircular a levemente alongada na direção NW, discordante da foliação regional associada à tectônica Brasiliana/Panafricana. Ocorre intrusivo em unidades paleoproterozoicas, representadas pelos ortognaisses bandados, relacionadas ao Complexo Caicó, e augen gnaisses, da Suíte Poço da Cruz. Xenólitos da Suíte Poço da Cruz ocorrem localmente. Não exibe evidências de tectônica dúctil, mostra apenas um padrão de estruturas frágeis de direção NNE-SSW (Fig. 2). A morfologia em campo é ressaltada por extensos paredões constituídos por conjunto de matacões, os quais compõem as bordas do stock. A idade ediacarana $(553 \pm 4 \mathrm{Ma})$ foi definida por Souza et al. (2015), através do método U-Pb em zircão (LA-ICP-MS).

Os trabalhos de campo, com auxílio de imagens de satélite, possibilitaram a separação de dois fácies texturais distintas no stock, ambos de natureza granítica. A fácies Tipo I (predominante) compõe a maior parte do stock, representada por um conjunto de matacões que a caracterizam e destacam o Stock Flores do relevo em seu entorno. As rochas exibem granulação média e coloração rosada. A fácies Tipo II ocorre de forma subordinada na porção S/SE arrasada do corpo, (claramente identificável em imagens de satélites) na qual predominam rochas de granulação fina com coloração acinzentada a rosada.

Enclaves máficos de composição diorítica (enclaves máficos microgranulares sensu Didier \& Barbarin, 1991) se concentram principalmente na fácies Tipo II, mostrando evidências de coexistência e mistura parcial de magmas (mingling e mixing; fig. 3). Estas feições são comuns em granitos ediacaranos da Província Borborema (Mariano \& Sial, 1990; Galindo, 1993; Galindo et al., 1995; Cavalcante et al., 2014; Nascimento et al., 2015) e em plutons graníticos descritos na literatura (Zorpi et al., 1989; Vernon, 1990, 2004; Hibbard, 1995; Barbarin, 2005). 


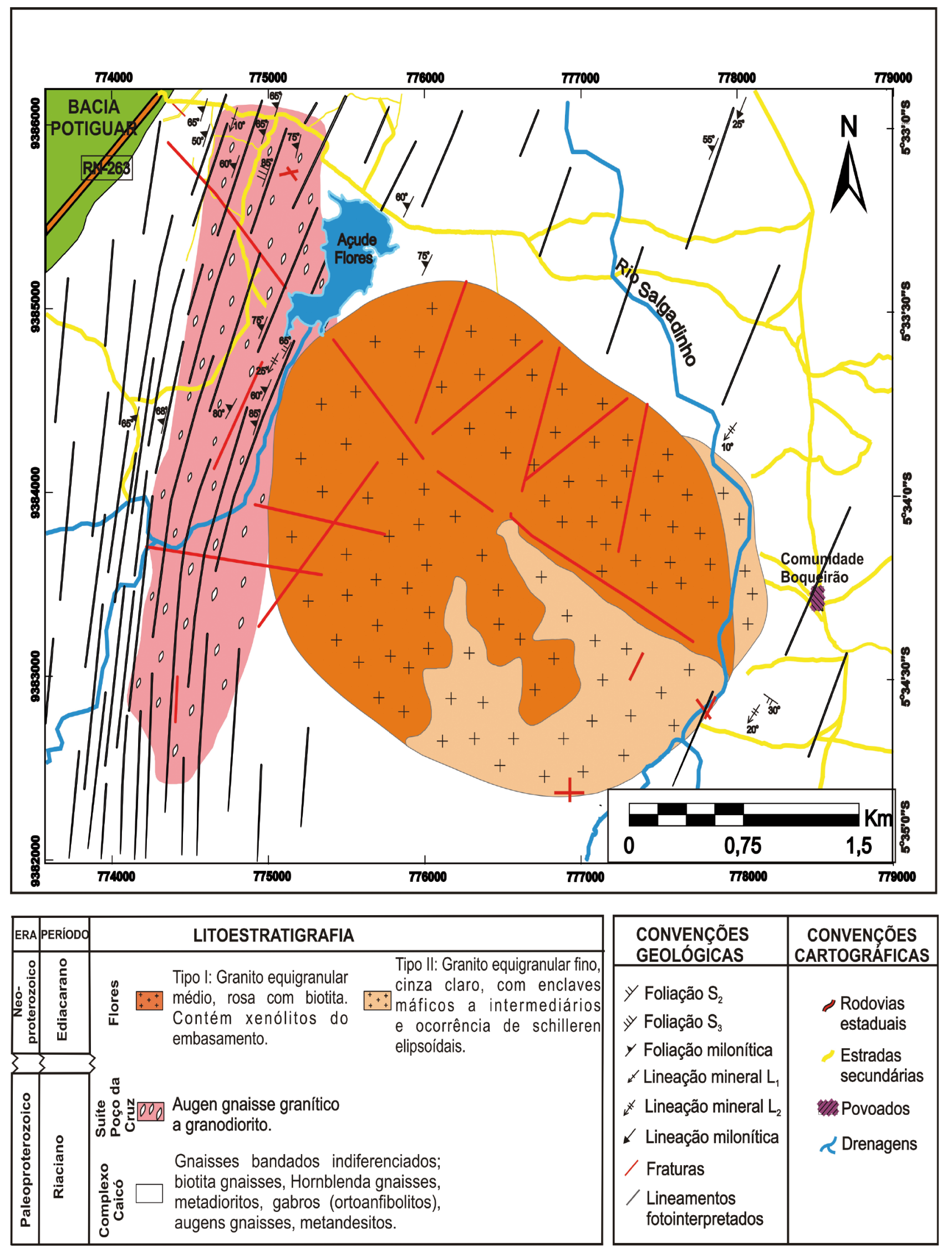

Figura 2. Mapa geológico do granito do Stock Flores.

Figure 2. Geological Map of the Flores Stock. 

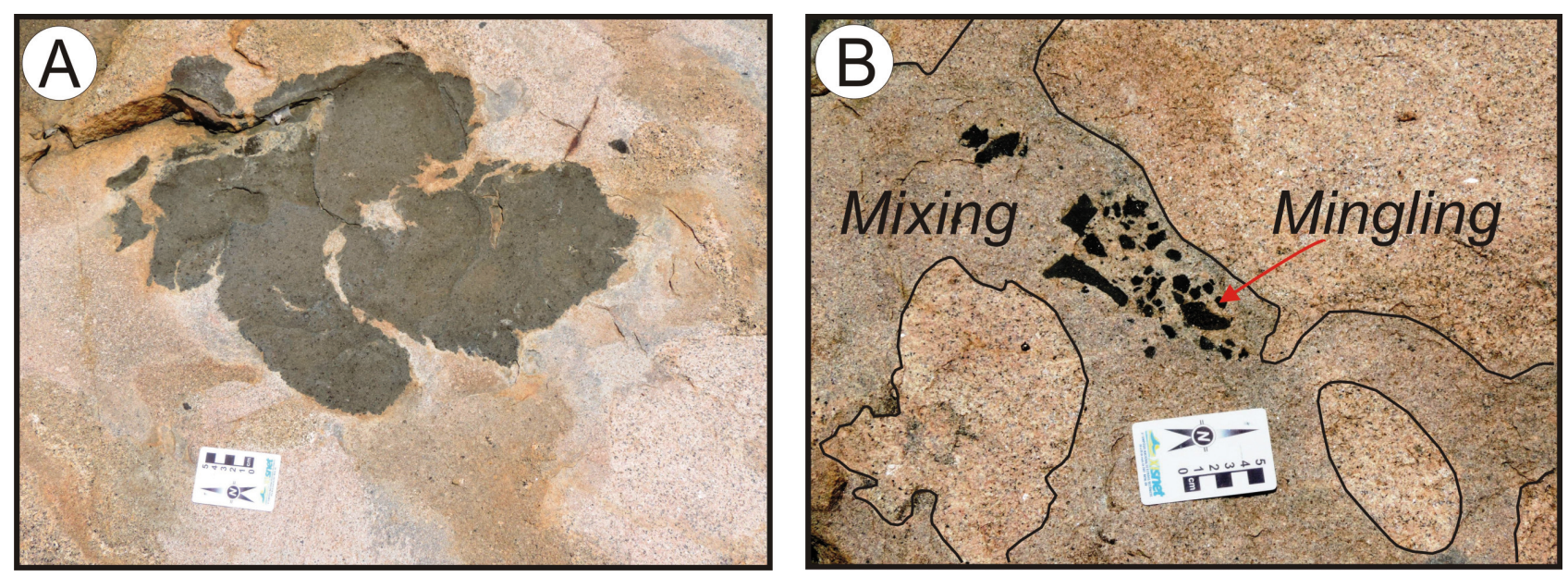

Figura 3. Enclaves magmáticos do Stock Flores. A) Enclave máfico diorítico; B) Feições de mingling e mixing magmáticos evidenciando diferentes composições magmáticas presentes na câmara do Stock Flores.

Figure 3. Enclaves to Flores Stock. A) Mafic enclave of diorite; B) Features of mingling and mixing magmatic showing different magmatic compositions in chamber Flores Stock.

Outros tipos de enclaves máficos, de particular interesse nos granitos do Stock Flores, são os schlieren elipsoidais, presentes no fácies Tipo II. Eles se apresentam com um núcleo máfico circundado por um ou mais anéis concêntricos (Fig. 4).

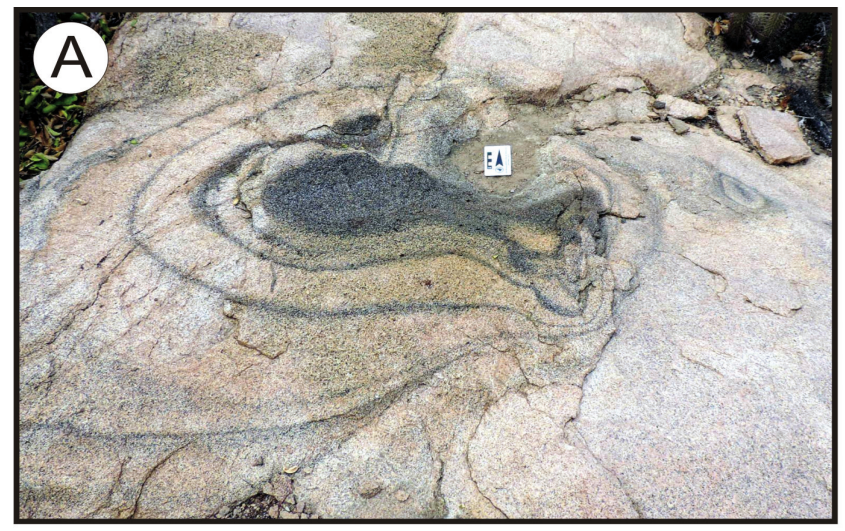

Este tipo de estrutura possibilita a obtenção de informações sobre fluxo de magma que por sua vez, contribuem para a compreensão da dinâmica interna da câmara magmática.

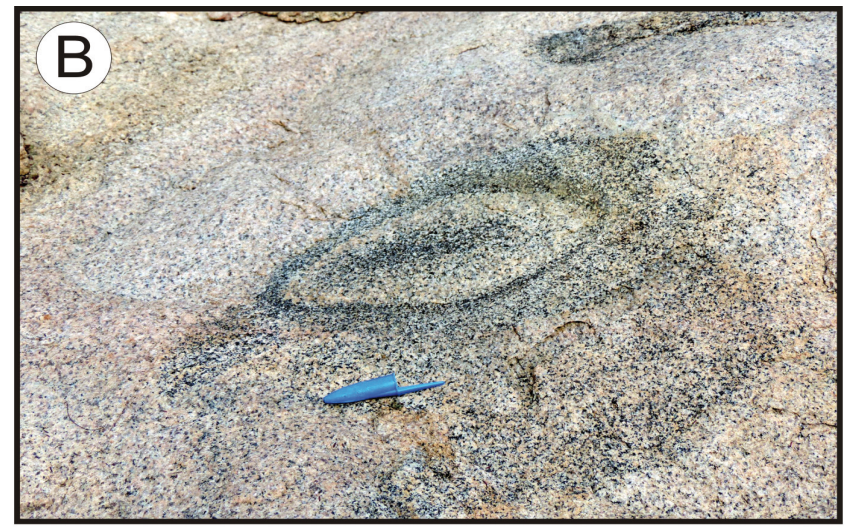

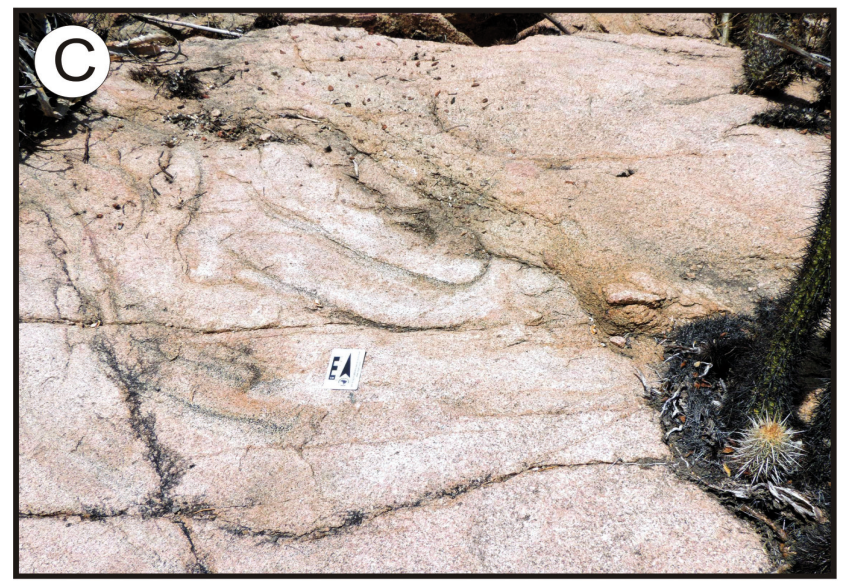

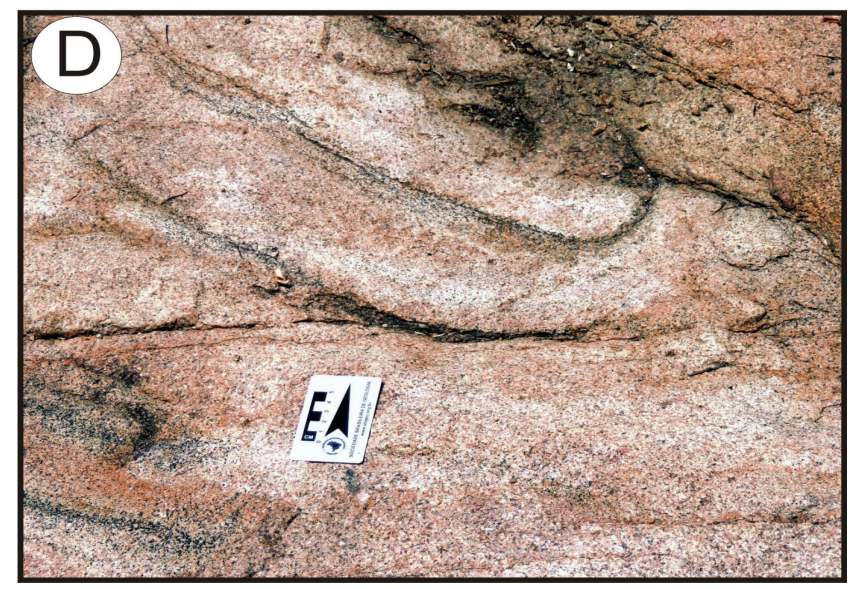

Figura 4. Estruturas de schlieren elipsoidais. A e B) Schlieren elipsoidais exibindo um núcleo máfico circundado por um ou mais anéis concêntricos fechados; C e D) Seção dos schlieren elipsoidais não exibindo o núcleo máfico.

Figure 4. Structures of the ellipsoidal schlieren. A and B) Ellipsoidal Schlieren exhibiting an mafic core surrounded by one or more closed concentric rings; $C$ and D) Section of ellipsoidal schlieren not displaying the mafic core.

\subsection{Materiais e métodos}

Para a realização desse trabalho foram con- feccionados mapas prévios a partir de imagens de Satélite (Landsat TM5; Geoeye) com tratamento de PDI nos softwares ER-Mapper® e Arcgis®. Fo- 
ram realizadas excursões a campo com o intuito de reconhecer e mapear a área de trabalho, bem como coletar material para a realização de análises petrográficas e geoquímicas. Doze lâminas delgadas foram descritas utilizando-se microscópio ótico petrográfico Leica DMLP. Para o cálculo das porcentagens modais das lâminas descritas, foi realizada a contagem de mil pontos por lâmina com o auxílio do dispositivo charriot, acoplado ao microscópio, e do programa de identificação de rochas Hardledge ®. Para a classificação e nomenclatura das rochas, foi utilizada a terminologia proposta pela IUGS (Streckeisen, 1976). Para a caracterização litogeoquímica realizou-se a preparação de quinze amostras incluindo fragmentação até 1-3cm em britador de mandíbula, seguido de redução a pó em moinhos de anéis de tungstênio. As amostras foram analisadas pelo ACME-Analytical Laboratorie LTDA, o qual quantificou os elementos maiores (Espectrometria de Emissão Atômica com Plasma Acoplado Indutivamente - ICP-OES), traços e terras raras (Espectrometria de Massas com Plasma Acoplado Indutivamente - ICP-MS). A perda ao fogo foi calculada pela diferença de peso após aquecimento de $0,2 \mathrm{~g}$ de amostra a $2000^{\circ} \mathrm{C}$. $\mathrm{O}$ erro analítico é menor que 5\% para óxidos e de 10 a $15 \%$ para os elementos traços. Para complementar a caracterização geoquímica os parâmetros normativos CIPW foram calculados com o auxílio do programa GCDkit ${ }$.

\section{Resultados}

\subsection{Petrografia e microtexturas do Stock Flores}

As rochas de ambas as fácies do Stock Flores são composicionalmente monzogranitos hololeucocráticos ( $\mathrm{M}<6 \%$; Fig. 5), com assembleia mineral similar e, como tal serão descritas conjuntamente. Quartzo, K-feldspato e plagioclásio representam os minerais félsicos dominantes ( $>94 \%$ ). A biotita é o máfico dominante $(<5 \%)$, titanita, allanita, apatita, zircão, minerais opacos e fluorita, os acessórios. Como minerais secundários relacionados a fluídos em estágio subsolídus, ocorrem clorita, epídoto, mica branca e carbonato (Tab. 1).

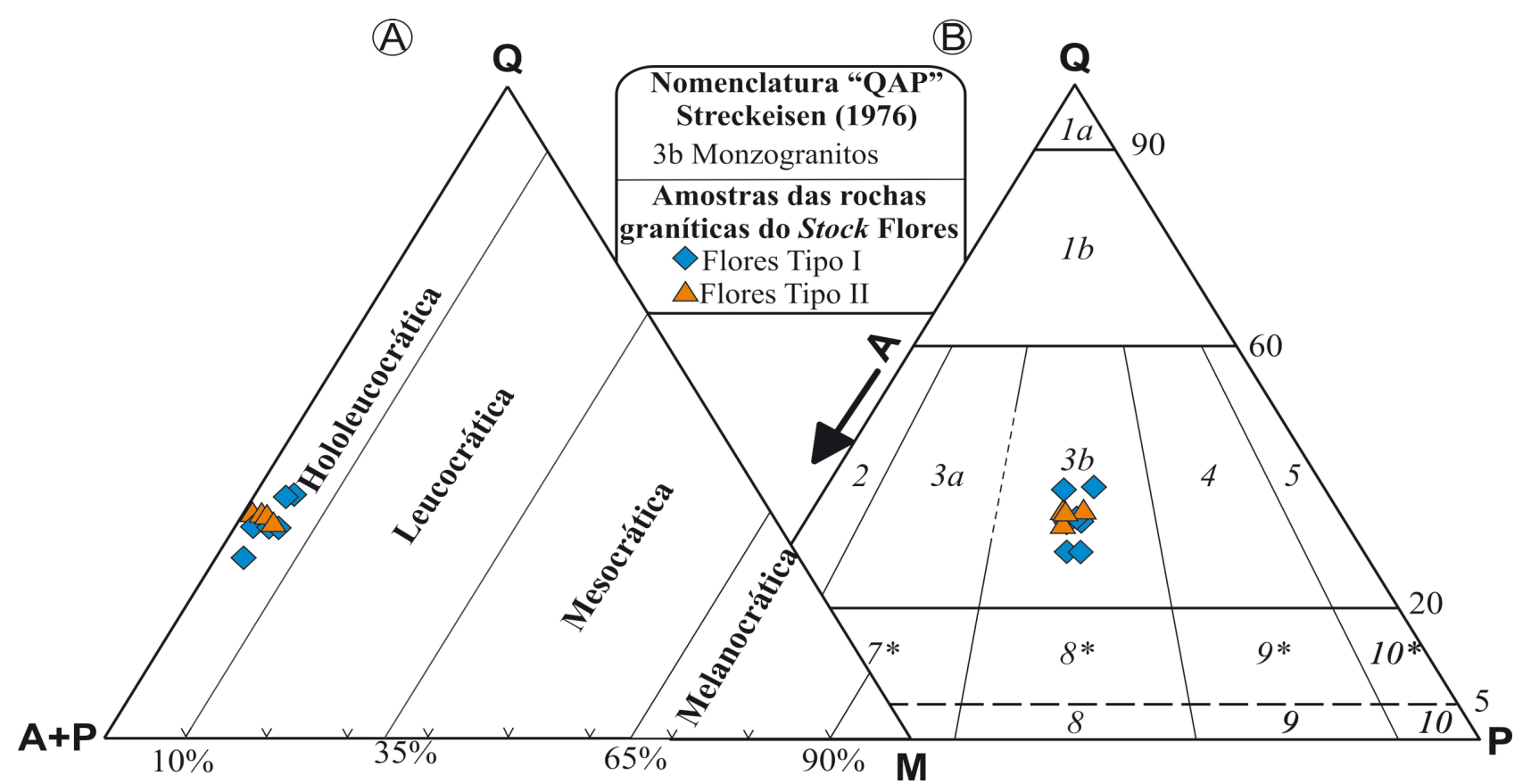

Figura 5. Classificação das rochas plutônicas estudadas com base nos diagramas QA+PM (A) e QAP (B) (Streckeisen, 1976; Le Maitre, 2002).

Figure 5. Classification of plutonic rocks studied based on QA + PM (A) and QAP (B) diagrams (Streckeisen, 1976; Le Maitre, 2002).

Os cristais de plagioclásio apresentam-se anédricos a subédricos com até 5,0 $\mathrm{mm}$ de comprimento, podem apresentar zonação normal (núcleos mais alterados), comumente mostram maclas polissiténticas bem definidas, sendo a maioria do tipo albita, e inclusões de biotita, zircão e apatita. Textura mirmequítica, principalmente do tipo bulbosa, está presente no contato com o K-feldspato.
Alteração para epídoto granular, carbonato e mica branca, é relativamente comum (Fig. 6A). Química mineral por microssonda eletrônica (Galindo et al., 2012) indica composição oligoclásica sódica com $\mathrm{An}_{12-13 \%}{ }^{*}$

O K-feldspato ocorre como cristais anédricos a subédricos com até $6 \mathrm{~mm}$ no seu eixo maior, exibindo o padrão de macla tartan (padrão em gra- 
de das maclas Albita versus Periclina). Texturas pertíticas (tipos fios e filetes) e, localizadamente, granofírica são encontradas. Inclusões de plagio- clásio, quartzo, apatita, biotita, titanita e minerais opacos são comuns (Fig. 6B, C).

Tabela 1. Composição modal das rochas que compõem o Stock Flores. Q: Quartzo; A: Feldspato alcalino; P: Plagioclásio. Table 1. Modal composition of rocks that making up the Flores Stock. Q: Quartz; A: alkali feldspar; P: plagioclase.

\begin{tabular}{|c|c|c|c|c|c|c|c|c|c|c|c|c|}
\hline \multirow{2}{*}{\begin{tabular}{c|} 
Fácies \\
Amostra \\
$(\%)$ \\
\end{tabular}} & \multicolumn{8}{|c|}{ Flores Tipo I } & \multicolumn{4}{|c|}{ Flores Tipo II } \\
\hline & $\begin{array}{c}\text { VF- } \\
\text { 04A }\end{array}$ & $\begin{array}{l}\text { VF- } \\
05\end{array}$ & $\begin{array}{l}\text { VF- } \\
16\end{array}$ & $\begin{array}{l}\text { VF- } \\
\text { 30B }\end{array}$ & $\begin{array}{l}\text { VF- } \\
\text { 30D }\end{array}$ & $\begin{array}{l}\text { VF- } \\
31\end{array}$ & $\begin{array}{l}\text { VF- } \\
42\end{array}$ & $\begin{array}{l}\text { VF- } \\
\text { 13B }\end{array}$ & $\begin{array}{l}\text { VF- } \\
19\end{array}$ & $\begin{array}{l}\text { VF- } \\
27\end{array}$ & $\begin{array}{l}\text { VF- } \\
\text { 30A }\end{array}$ & $\begin{array}{l}\text { VF- } \\
54\end{array}$ \\
\hline Quartzo & 27,7 & 29,0 & 35,6 & 31,9 & 35,8 & 27,9 & 31,9 & 33,6 & 30,6 & 33,3 & 33,2 & 32,5 \\
\hline Plagioclásio & 34,4 & 28,6 & 31,0 & 31,8 & 28,8 & 33,4 & 32,5 & 32,9 & 30,5 & 30,9 & 30,0 & 34,4 \\
\hline K-Feldspato & 33,3 & 36,6 & 26,7 & 33,3 & 31,1 & 34,7 & 30,8 & 30,7 & 32,1 & 32,9 & 32,6 & 28,5 \\
\hline Biotita & 3,2 & 4,7 & 4,0 & 2,4 & 3,9 & 3,1 & 4,4 & 1,5 & 4,4 & 1,1 & 3,5 & 4,5 \\
\hline Titanita & $\operatorname{Tr}$ & $\operatorname{Tr}$ & $\operatorname{Tr}$ & $\operatorname{Tr}$ & $\operatorname{Tr}$ & $\operatorname{Tr}$ & $\operatorname{Tr}$ & $\operatorname{Tr}$ & 0,2 & $\operatorname{Tr}$ & $\operatorname{Tr}$ & $\operatorname{Tr}$ \\
\hline Alanita & $\operatorname{Tr}$ & $\operatorname{Tr}$ & $\operatorname{Tr}$ & $\operatorname{Tr}$ & $\operatorname{Tr}$ & 0,4 & - & 0,2 & 0,4 & 0,2 & $\operatorname{Tr}$ & $\operatorname{Tr}$ \\
\hline Apatita & $\operatorname{Tr}$ & $\operatorname{Tr}$ & $\operatorname{Tr}$ & $\operatorname{Tr}$ & $\operatorname{Tr}$ & $\operatorname{Tr}$ & $\operatorname{Tr}$ & $\operatorname{Tr}$ & $\operatorname{Tr}$ & $\operatorname{Tr}$ & $\operatorname{Tr}$ & $\operatorname{Tr}$ \\
\hline Opacos & 0,5 & 0,4 & 1,0 & 0,2 & 0,2 & 0,2 & - & 0,7 & 0,7 & 0,2 & $\operatorname{Tr}$ & 0,1 \\
\hline Zircão & $\mathrm{Tr}$ & $\operatorname{Tr}$ & $\operatorname{Tr}$ & $\operatorname{Tr}$ & $\operatorname{Tr}$ & $\operatorname{Tr}$ & $\operatorname{Tr}$ & $\operatorname{Tr}$ & $\operatorname{Tr}$ & $\operatorname{Tr}$ & $\operatorname{Tr}$ & $\operatorname{Tr}$ \\
\hline Fluorita & ---- & ---- & --- & ---- & ---- & $\operatorname{Tr}$ & --- & ---- & ---- & ---- & ---- & ---- \\
\hline Clorita & $\mathrm{Tr}$ & $\operatorname{Tr}$ & 0,1 & 0,1 & - & 0,2 & - & $\operatorname{Tr}$ & 0,3 & 0,4 & 0,3 & $\operatorname{Tr}$ \\
\hline Muscovita & 0,9 & 0,7 & 1,6 & 0,3 & 0,2 & 0,1 & 0,4 & - & 0,8 & 1,0 & 0,4 & $\operatorname{Tr}$ \\
\hline Total & 100,0 & 100,0 & 100,0 & 100,0 & 100,0 & 100,0 & 100,0 & 100,0 & 100,0 & 100,0 & 100,0 & 100,0 \\
\hline $\mathrm{Q}$ & 29,0 & 30,8 & 38,2 & 32,9 & 37,4 & 29,1 & 33,5 & 34,6 & 32,8 & 34,3 & 34,6 & 34,0 \\
\hline A & 34,9 & 30,4 & 28,6 & 34,3 & 32,5 & 36,1 & 32,3 & 31,6 & 34,4 & 33,8 & 34,0 & 32,0 \\
\hline $\mathrm{P}$ & 36,1 & 30,3 & 33,2 & 32,8 & 30,1 & 34,7 & 34,1 & 33,8 & 32,7 & 31,8 & 31,3 & 34,0 \\
\hline$\sum$ Máficos & 3,7 & 5,1 & 5,0 & 2,6 & 4,1 & 3,7 & 4,4 & 2,8 & 5,7 & 1,5 & 3,5 & 4,6 \\
\hline $\mathrm{A}+\mathrm{P}$ & 67,6 & 65,2 & 63,6 & 65,1 & 59,9 & 68,1 & 63,3 & 63,9 & 62,6 & 63,8 & 63,0 & 62,9 \\
\hline
\end{tabular}

O quartzo ocorre em cristais anédricos com dimensões de até $6 \mathrm{~mm}$, exibem no geral contatos curvos a irregulares com plagioclásio e microclina. Comumente apresenta extinção ondulante e fraturamento de cristais indicando deformação em estado sólido. Ocorre ainda como cristais vermiculares e goticulares associados às texturas mirmequíticas e granofíricas.

A biotita exibe forte pleocróismo em tons marrom e verde, hábito placoide/lamelar, subédrica, sendo comum apresentar processo de cloritização bem como inclusões de minerais opacos e zircão (Fig. 6D). Análise química por microssonda eletrônica mostra composições enriquecidas na molécula de annita com razões $\mathrm{Fe} /(\mathrm{Fe}+\mathrm{Mg})>0,7 \mathrm{e}$ $\mathrm{Al}^{\mathrm{lV}}<2,4$ (Galindo et al., 2012). Os minerais opacos primários são euédricos a subédricos, atingindo até $0,2 \mathrm{~mm}$, ou anédricos derivados da desestabilização de biotita para clorita. A titanita ocorre como cristais euédricos a euédricos usualmente losângulares de cor marrom pálida, com dimensão de 0,3 até $1,00 \mathrm{~mm}$. A allanita se apresenta como cristais subédricos zonados, com cor amarela acas- tanhada com dimensão de $0,4 \mathrm{~mm}$ a $1,0 \mathrm{~mm}$, e por vezes exibe processos de metamictização. Apatita e zircão aparecem como pequenos cristais incolores, euédricos a subédricos, usualmente inclusos em plagioclásio e biotita. A fluorita é comumente subédrica a anédrica, incolor a levemente lilás.

Muscovita e clorita ocorrem essencialmente como produtos de alteração da biotita, revelando-se, por vezes, verdadeiros pseudomorfos. Associada a cloritização ocorre o desenvolvimento de finos opacos ao longo dos planos de clivagens da biotita. Carbonato, epídoto e mica branca ocorrem como produto de alteração do plagioclásio, preenchendo fraturas ou no interior dos grãos.

\subsection{Geoquímica do Stock Flores}

\subsubsection{Caracterização Litogeoquímica}

Os resultados das análises químicas para as rochas do Stock Flores, bem como os cálculos normativos (CIPW) estão aqui apresentados da seguinte maneira: Elementos maiores (Tab. 2); Mine- 
rais normativos (CIPW; Tab. 3); Elementos traços (Tab. 4); Elementos terras raras (Tab. 5).

As rochas do Stock Flores são enriquecidas em $\mathrm{SiO}_{2}\left(71.43\right.$ - 74.87\%), $\mathrm{Al}_{2} \mathrm{O}_{3}(12,99-13,93 \%)$, e $\mathrm{K}_{2} \mathrm{O}$ (4,95-6,03\%), e empobrecidas em MgO $(<0.5 \%)$, $\mathrm{CaO}(\leq 1,4 \%), \mathrm{Fe}_{2} \mathrm{O}_{3}(<2,3 \%), \mathrm{TiO}_{2}(<0.4 \%)$ e $\mathrm{P}_{2} \mathrm{O}_{5}$ $(<0,8 \%)$. Exibem caráter peraluminoso (razão mo-
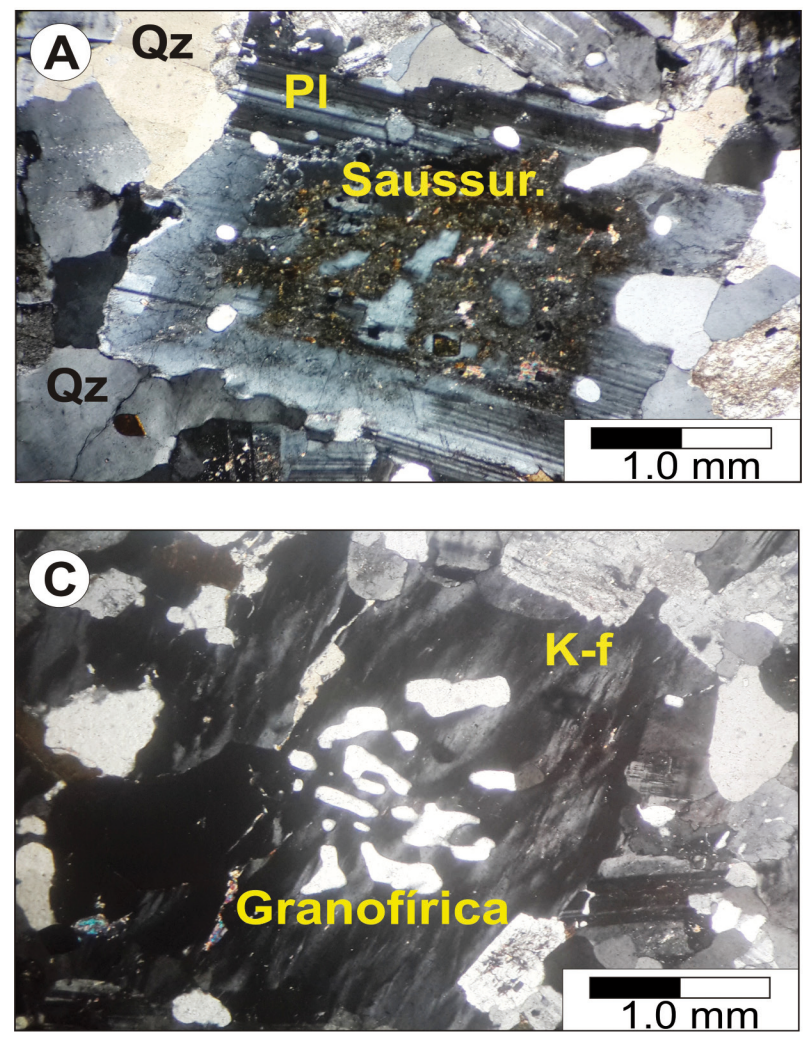

lecular A/CNK de 0,98 a 1,08), sempre com coríndon normativo, excetuando-se uma amostra.

Diagramas de variação do tipo Harker mostram correlações negativas para $\mathrm{Al}_{2} \mathrm{O}_{3}, \mathrm{Fe}_{2} \mathrm{O}_{3}, \mathrm{CaO}$, $\mathrm{TiO}_{2}, \mathrm{~K}_{2} \mathrm{O}, \mathrm{Zr}$, e em menor grau para Ba e Sr (Fig. 7). Outros elementos/óxidos mostram dispersão $\left(\mathrm{Na}_{2} \mathrm{O}, \mathrm{Rb}, \mathrm{Nb}\right.$ e $\mathrm{Y}$, por exemplo).
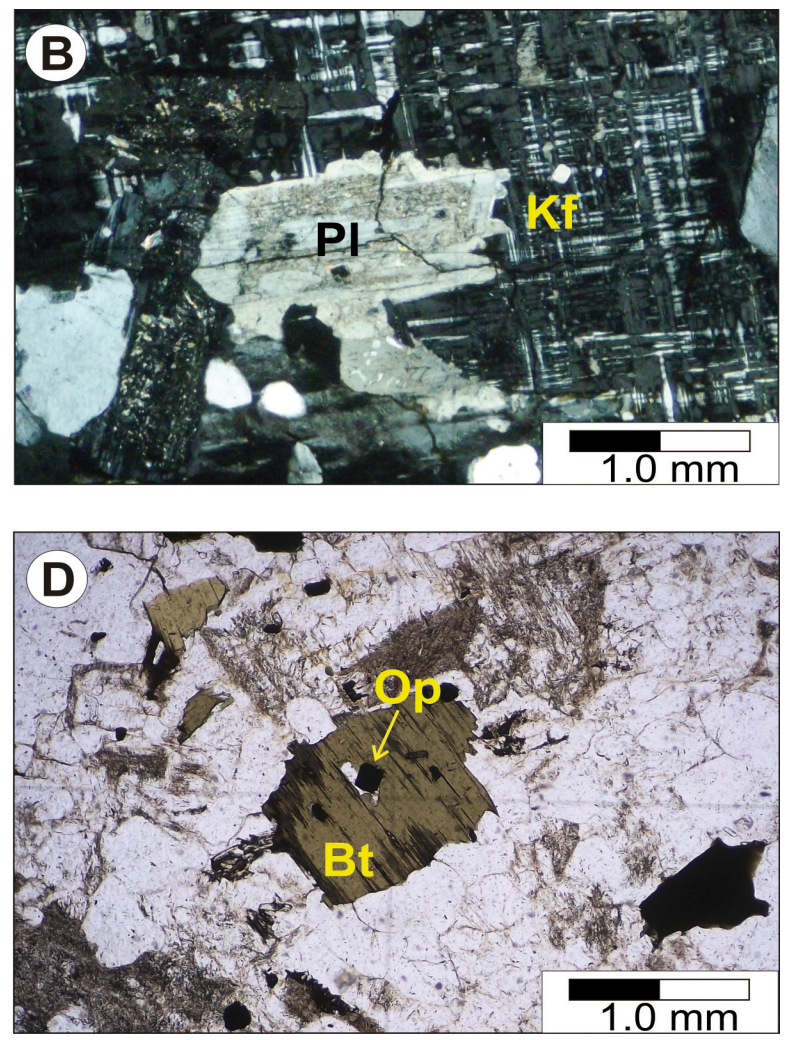

Figura 6. Fotomicrografias dos minerais que compõem a paragênese do Stock Flores. A) Cristal zonado de Plagioclásio (Pl) com centro mais cálcico exibindo processo de saussuritização; B) Cristal de K- Feldspato (Kf) com inclusão de cristal de plagioclásio zonado; C) Cristal de K-feldspato com textura granofírica; D) Cristal de biotita com inclusão de opaco euédrico (magnetita). Figure 6. Photomicrographs of minerals that make up the paragenesis Flores Stock. A) Zoned crystal of the plagioclase (PI) with center more calcium showing saussuritization process; B) K-feldspar crystal (Kf) with inclusion of plagioclase zoned crystal; C) K-feldspar crystal with granophyric texture; D) Biotite crystal with inclusion of euhedral opaque (magnetite).

O padrão dos elementos terras raras-ETRs (Fig. 8A) exibe um moderado grau de enriquecimento de ETRL em relação aos ETRP com razões $\mathrm{La}_{\mathrm{N}} / \mathrm{Yb}_{\mathrm{N}}$ entre 4,59\% - 30,85. 0 perfil de curva exposto no diagrama exibe uma inclinação moderada para os ETRL (razões $\mathrm{La}_{\mathrm{N}} / \mathrm{Sm}_{\mathrm{N}}$ entre $3,41-7,22$ ) e uma inclinação suavizada/horizontalizada para os ETRP (razões $\mathrm{Gd}_{\mathrm{N}} / \mathrm{Yb}_{\mathrm{N}}$ entre 0,97 - 2,46), além de uma marcante anomalia negativa de Eu. (Eu/ Eu*entre 0,24- 0,55).

Para a análise do comportamento conjunto de elementos maiores/menores ( $\mathrm{K}, \mathrm{P}$ e Ti) e traços e ERTs (Ba, Rb, Th, Nb, Ta, Sr, Zr, Hf e Y; La, Ce, Nd, $\mathrm{Sm}, \mathrm{Tb}, \mathrm{Tm}$ e $\mathrm{Yb}$ ) foi utilizado diagramas multielementos do tipo spidergrams. 0 espectro do diagrama (Fig. 8B) exibe um enriquecimento em relação ao condrito, com um caimento suave do $\mathrm{Rb}$ ao $\mathrm{Yb}$, com anomalias negativas para $\mathrm{Nb}, \mathrm{Sr}, \mathrm{P}$ e Ti.

\subsubsection{O Stock Flores no contexto de séries magmáti-} cas, ambientes tectônicos e tipologia de granitóides

A caracterização da série/associação magmática a qual as rochas do Stock Flores estão relacionadas foi feita a partir de variados diagramas discriminantes binários de associações magmáticas (Fig. 9), tanto aqueles que definem trends (TAS Lameyre, 1987; R1xR2 - De La Roche et al., 1980), quanto os que definem campos (Wright, 1969; Rogers \& Greenberg, 1981; Sylvester, 1989; Frost et al., 2001).

No diagrama TAS as amostras distribuem-se entre as linhas de tendência monzonítica e alcalina, e no campo alcalino quando considerado a linha divisória alcalino/subalcalino proposta por Miyashiro (1978; fig. 9A). No diagrama R1x R2 as amostras se distribuem ao longo da tendência al- 
calina de rochas enriquecidas em sílica (Fig. 9B). No diagrama proposto por Rogers \& Greenberg (1981) as amostras do Stock Flores posicionam-se no campo alcalino (Fig. 9C). 0 índice de alcalinidade (Wright, 1969) também caracteriza o Stock Flores como parte de uma suíte alcalina (Fig. 9D). Da mesma forma, o diagrama de Sylvester (1989) caracteriza as rochas do Stock Flores como parte de uma suíte alcalina, transicionando para o subdomínio dos granitos alcalinos similares a granitos calcioalcalinos fortemente fracionados (Figura 9E). Por fim, no diagrama de Frost et al. (2001) as amostras analisadas plotam predominantemente no campo Ferroso, comum aos granitos alcalinos (Fig. 9F).

Tabela 2. Análise química dos elementos maiores (\% em peso) para rochas do Stock Flores.

Table 2. Chemical analysis of major elements (\% by weight) for rocks of the Flores stock.

\begin{tabular}{|c|c|c|c|c|c|c|c|c|c|c|c|c|c|c|}
\hline \multicolumn{15}{|c|}{ Elementos maiores em \% peso } \\
\hline \multirow{2}{*}{$\begin{array}{c}\text { Fácies } \\
\text { Óxidos }\end{array}$} & \multicolumn{10}{|c|}{ Flores Tipo I } & \multicolumn{4}{|c|}{ Flores Tipo II } \\
\hline & VF04A & SF26 & SF03 & SF38 & SF25 & VF05 & VF31 & VF30B & SF40 & VF30D & VF27 & VF13B & VF30A & VF25 \\
\hline $\mathrm{SiO}_{2}$ & 71,52 & 72,15 & 72,73 & 72,74 & 73,06 & 73,30 & 73,60 & 73,80 & 74,12 & 74,63 & 73,59 & 74,43 & 74,52 & 74,87 \\
\hline $\mathrm{Al}_{2} \mathrm{O}_{3}$ & 13,72 & 13,79 & 13,60 & 13,73 & 13,38 & 13,52 & 13,54 & 13,54 & 13,15 & 13,37 & 13,42 & 12,99 & 13,16 & 13,37 \\
\hline $\mathrm{Fe}_{2} \mathbf{O}_{3}$ & 2,15 & 2,16 & 2,14 & 1,68 & 2,05 & 1,75 & 1,74 & 1,40 & 1,55 & 1,38 & 1,38 & 1,67 & 1,39 & 1,30 \\
\hline MnO & 0,03 & 0,03 & 0,04 & 0,04 & 0,03 & 0,03 & 0,03 & 0,03 & 0,03 & 0,03 & 0,02 & 0,02 & 0,03 & 0,05 \\
\hline MgO & 0,27 & 0,28 & 0,25 & 0,17 & 0,23 & 0,19 & 0,19 & 0,12 & 0,14 & 0,17 & 0,15 & 0,10 & 0,17 & 0,13 \\
\hline $\mathrm{CaO}$ & 1,32 & 1,04 & 1,01 & 1,16 & 0,94 & 0,96 & 0,94 & 0,82 & 0,92 & 0,86 & 0,97 & 1,11 & 0,85 & 0,64 \\
\hline $\mathrm{Na}_{2} \mathrm{O}$ & 3,30 & 3,33 & 3,32 & 3,32 & 3,25 & 3,34 & 3,40 & 3,45 & 3,42 & 3,57 & 3,22 & 3,31 & 3,37 & 3,19 \\
\hline $\mathbf{K}_{2} \mathbf{O}$ & 5,69 & 5,75 & 5,37 & 5,68 & 5,50 & 5,44 & 5,47 & 5,22 & 4,96 & 5,00 & 5,86 & 4,95 & 5,12 & 5,54 \\
\hline $\mathrm{Ti}_{2} \mathrm{O}$ & 0,42 & 0,31 & 0,27 & 0,20 & 0,24 & 0,19 & 0,20 & 0,13 & 0,16 & 0,13 & 0,13 & 0,22 & 0,14 & 0,13 \\
\hline $\mathbf{P}_{2} \mathbf{O}_{5}$ & 0,06 & 0,07 & 0,06 & 0,03 & 0,06 & 0,04 & 0,05 & 0,03 & 0,02 & 0,03 & 0,02 & 0,02 & 0,03 & 0,02 \\
\hline $\mathbf{P F}$ & 1,30 & 0,70 & 0,90 & 0,90 & 0,90 & 1,10 & 0,70 & 1,40 & 1,20 & 0,70 & 1,10 & 1,00 & 1,10 & 0,60 \\
\hline Total & 99,81 & 99,61 & 99,69 & 99,65 & 99,64 & 99,88 & 99,87 & 99,91 & 99,67 & 99,91 & 99,90 & 99,85 & 99,90 & 99,87 \\
\hline $\mathrm{Na}_{2} \mathrm{O}+\mathrm{K}_{2} \mathrm{O}$ & 8,99 & 9,08 & 8,69 & 9,00 & 8,75 & 8,78 & 8,87 & 8,67 & 8,38 & 8,57 & 9,08 & 8,26 & 8,49 & 8,73 \\
\hline $\mathrm{K}_{2} \mathrm{O} / \mathrm{Na}_{2} \mathrm{O}$ & 1,72 & 1,73 & 1,62 & 1,71 & 1,69 & 1,63 & 1,61 & 1,51 & 1,45 & 1,40 & 1,82 & 1,50 & 1,52 & 1,74 \\
\hline A/(NK) & 1,18 & 1,18 & 1,21 & 1,18 & 1,18 & 1,19 & 1,18 & 1,20 & 1,20 & 1,18 & 1,15 & 1,20 & 1,19 & 1,19 \\
\hline & 0,98 & 1,01 & 1,04 & 1,00 & 1,03 & 1,03 & 1,02 & 1,06 & 1,04 & 1,04 & 1,00 & 1,01 & 1,04 & 1,08 \\
\hline $\mathrm{M}=\frac{\mathrm{Na}+\mathrm{K}+\mathrm{Ca}}{\mathrm{Al}^{*} \mathrm{Si}}$ & 1,50 & 1,44 & 1,40 & 1,45 & 1,40 & 1,40 & 1,40 & 1,35 & 1,37 & 1,36 & 1,43 & 1,40 & 1,36 & 1,31 \\
\hline
\end{tabular}

No que diz respeito ao ambiente tectônico para o alojamento do Stock Flores, foram levadas em consideração, além das relações de campo (critérios de intrusão, ausência de feições dúcteis, rochas essencialmente isotrópicas, etc.), a análise de diagramas geoquímicos discriminantes de ambiente tectônico (Pearce et al., 1984; Harris et al., 1986; Maniar \& Picolli, 1989; Pearce, 1996). Nestes diagramas rochas do Stock Flores mostram afinidade geoquímica com granitos de ambientes tectonicamente estáveis, pós-colisionais e/ou pós-orogênicos, ressaltando-se que na proposta de Pearce et al. (1984) há uma coerência com granitos intraplacas (Figura 10).

Tabela 3. Composição dos minerais normativos CIPW (\% peso) para as rochas do Stock Flores. Table 3. Composition of normative minerals CIPW (\% weight) for rocks of the Flores Stock.

\begin{tabular}{c|cccccccccc|cccc}
\hline Minerais Normativos (CIPW) em \% em peso \\
\hline Fácies & \multicolumn{10}{c}{ Flores Tipo I } & \multicolumn{10}{c}{10} \\
\hline Minerais & VF04A & SF26 & SF03 & SF38 & SF25 & VF05 & VF31 & VF30B & SF40 & VF30D & VF27 & VF13B & VF30A & VF25 \\
\hline Quartzo & 27,56 & 28,32 & 30,50 & 29,03 & 30,92 & 30,82 & 30,73 & 31,90 & 33,12 & 32,78 & 30,18 & 33,76 & 33,33 & 33,60 \\
Coríndon & 0,00 & 0,36 & 0,63 & 0,08 & 0,51 & 0,49 & 0,44 & 0,79 & 0,53 & 0,59 & 0,06 & 0,21 & 0,60 & 1,01 \\
Ortoclásio & 33,63 & 33,98 & 31,73 & 33,57 & 32,50 & 32,15 & 32,33 & 30,85 & 29,31 & 29,59 & 34,63 & 29,25 & 30,26 & 32,74 \\
Albita & 27,92 & 28,17 & 28,09 & 28,09 & 27,50 & 28,26 & 28,77 & 29,19 & 28,94 & 30,21 & 27,24 & 28,01 & 28,51 & 26,99 \\
Hematita & 2,15 & 2,16 & 2,14 & 1,68 & 2,05 & 1,75 & 1,74 & 1,40 & 1,55 & 1,38 & 1,38 & 1,67 & 1,39 & 1,30 \\
Titanita & 0,24 & 0,00 & 0,00 & 0,00 & 0,00 & 0,00 & 0,00 & 0,00 & 0,00 & 0,00 & 0,00 & 0,00 & 0,00 & 0,00 \\
Rutilo & 0,29 & 0,20 & 0,22 & 0,15 & 0,21 & 0,16 & 1,67 & 0,10 & 0,13 & 0,10 & 0,11 & 0,20 & 0,11 & 0,07 \\
Apatita & 0,14 & 0,17 & 0,14 & 0,07 & 0,14 & 0,09 & 0,12 & 0,07 & 0,05 & 0,07 & 0,05 & 0,05 & 0,07 & 0,47 \\
Soma & 98,48 & 98,98 & 98,79 & 98,75 & 98,74 & 98,76 & 99,16 & 98,54 & 98,47 & 99,27 & 98,74 & 98,82 & 98,77 & 99,24 \\
\hline
\end{tabular}


Tabela 4. Análise química dos elementos traços (ppm) para as rochas do Stock Flores.

Table 4. Chemical analysis of trace elements (ppm) for rocks of the Flores Stock.

\begin{tabular}{|c|c|c|c|c|c|c|c|c|c|c|c|c|c|c|}
\hline \multicolumn{15}{|c|}{ Elementos Traços em PPM } \\
\hline \multirow{2}{*}{\begin{tabular}{c|} 
Fácies \\
Amostras \\
\end{tabular}} & \multicolumn{10}{|c|}{ Flores Tipo I } & \multicolumn{4}{|c|}{ Flores Tipo II } \\
\hline & VF04A & SF26 & SF03 & SF38 & SF25 & VF05 & VF31 & VF30B & SF40 & VF30D & VF27 & VF13B & VF30A & VF25 \\
\hline $\mathrm{Zr}$ & 322,3 & 298,8 & 292,0 & 206,4 & 277,2 & 213,8 & 208,9 & 137,3 & 173,7 & 110,5 & 67,4 & 62,5 & 123,5 & 135,2 \\
\hline $\mathbf{N i}$ & 71,0 & 2,5 & 1,7 & 2,2 & 2,5 & 50,3 & 48,2 & 33,7 & 2,0 & 31,8 & 20,7 & 96,1 & 36,3 & 61,2 \\
\hline $\mathbf{Y}$ & 80,9 & 35,3 & 35,3 & 35,3 & 35,3 & 39,4 & 36,1 & 33,9 & 35,3 & 40,7 & 24,2 & 76,0 & 46,8 & 62,6 \\
\hline Nb & 58,2 & 55,5 & 48,5 & 39,7 & 33,8 & 31,2 & 28,8 & 26,9 & 42,9 & 40,6 & 21,3 & 49,8 & 42,7 & 31,2 \\
\hline Ta & 6,8 & 3,8 & 3,2 & 4,2 & 2,7 & 2,9 & 3,0 & 2,3 & 4,0 & 4,9 & 2,2 & 6,6 & 5,5 & 3,3 \\
\hline Th & 35,4 & 1,8 & 1,4 & 1,2 & 1,1 & 27,7 & 30,0 & 25,3 & 1,1 & 31,3 & 14,3 & 72,5 & 32,9 & 28,3 \\
\hline Hf & 9,3 & 8,9 & 8,6 & 6,9 & 8,7 & 7,5 & 7,1 & 5,5 & 6,3 & 4,4 & 2,4 & 2,7 & 5,0 & 5,4 \\
\hline Sm & 16,3 & 12,3 & 10,8 & 8,1 & 10,6 & 8,8 & 8,5 & 6,4 & 7,8 & 6,4 & 4,2 & 19,3 & 7,7 & 12,6 \\
\hline $\mathrm{Ce}+\mathrm{Y}+\mathrm{Nb}+\mathrm{Zr}$ & 629,0 & 540,9 & 540,7 & 401,5 & 522,2 & 416,6 & 398,7 & 281,5 & 352,4 & 263,6 & 162,2 & 424,9 & 292,0 & 349,5 \\
\hline $10^{3 *} \mathrm{Ga} / \mathrm{Al}$ & 3,65 & 3,13 & 3,48 & 3,20 & 3,30 & 3,48 & 3,17 & 3,26 & 3,55 & 3,47 & 3,15 & 3,41 & 3,51 & 3,37 \\
\hline $\mathrm{T}\left({ }^{\circ} \mathrm{C}\right)$ sat.Zr & 842,1 & 839,4 & 841,0 & 804,5 & 835,7 & 811,8 & 809 & 776,1 & 795,5 & 756,9 & 713,5 & 710,2 & 766,7 & 777,6 \\
\hline
\end{tabular}

Tabela 5. Análise química dos elementos terras raras (ppm) para as rochas do Stock Flores.

Table 5. Chemical analysis of rare earth elements ( $\mathrm{ppm}$ ) for rocks of the Flores Stock.

\begin{tabular}{|c|c|c|c|c|c|c|c|c|c|c|c|c|c|c|}
\hline \multicolumn{15}{|c|}{ Elementos Terras Raras em PPM } \\
\hline \multirow{2}{*}{\begin{tabular}{c|} 
Fácies \\
Amostras
\end{tabular}} & \multicolumn{10}{|c|}{ Flores Tipo I } & \multicolumn{4}{|c|}{ Flores Tipo II } \\
\hline & VF04A & SF26 & SF03 & SF38 & SF25 & VF05 & VF31 & VF30B & SF40 & VF30D & VF27 & VF13B & VF30A & VF25 \\
\hline La & 88,5 & 81,9 & 88,9 & 61,8 & 91,6 & 70,3 & 65,7 & 46,0 & 50,4 & 37,4 & 25,7 & 119,0 & 41,9 & 76,4 \\
\hline $\mathrm{Ce}$ & 167,6 & 151,3 & 164,9 & 120,1 & 175,9 & 132,2 & 124,9 & 83,4 & 100,5 & 71,7 & 49,3 & 236,6 & 79,0 & 120,5 \\
\hline Pr & 19,4 & 18,1 & 19,0 & 13,1 & 19,7 & 14,4 & 13,9 & 9,9 & 11,6 & 8,7 & 5,7 & 27,4 & 10,0 & 16,8 \\
\hline Nd & 71,0 & 62,9 & 62,5 & 46,4 & 66,3 & 50,3 & 48,2 & 33,7 & 39,1 & 31,8 & 20,7 & 96,1 & 36,3 & 61,2 \\
\hline Sm & 16,3 & 12,3 & 10,8 & 8,1 & 10,7 & 8,8 & 8,5 & 6,4 & 7,8 & 6,4 & 4,2 & 19,3 & 7,7 & 12,6 \\
\hline Eu & 1,4 & 1,1 & 1,0 & 0,7 & 0,9 & 0,8 & 0,8 & 0,6 & 0,7 & 0,6 & 0,7 & 1,5 & 0,6 & 1,0 \\
\hline Gd & 16,4 & 11,4 & 9,8 & 7,2 & 7,2 & 7,5 & 7,2 & 5,6 & 6,5 & 6,6 & 4,1 & 16,7 & 7,3 & 12,4 \\
\hline $\mathbf{T b}$ & 2,8 & 1,8 & 1,4 & 1,2 & 1,1 & 1,2 & 1,1 & 0,8 & 1,1 & 1,1 & 0,7 & 2,7 & 1,3 & 1,9 \\
\hline Dy & 15,8 & 11,0 & 8,7 & 7,2 & 5,9 & 6,4 & 6,4 & 5,0 & 6,6 & 7,0 & 4,3 & 14,9 & 7,6 & 10,6 \\
\hline Ho & 3,1 & 2,1 & 1,7 & 1,4 & 1,1 & 1,2 & 1,3 & 1,0 & 1,4 & 1,4 & 0,9 & 2,9 & 1,6 & 2,2 \\
\hline Er & 8,8 & 5,7 & 4,8 & 4,1 & 3,5 & 3,8 & 3,8 & 3,0 & 4,3 & 4,5 & 2,6 & 8,1 & 5,1 & 6,0 \\
\hline $\mathbf{T m}$ & 1,2 & 0,8 & 0,7 & 0,5 & 0,5 & 0,6 & 0,6 & 0,5 & 0,7 & 0,7 & 0,4 & 1,1 & 0,8 & 0,8 \\
\hline $\mathbf{Y b}$ & 7,6 & 5,9 & 5,2 & 4,1 & 3,9 & 4,2 & 4,1 & 3,2 & 5,2 & 5,5 & 2,8 & 7,1 & 6,0 & 5,6 \\
\hline Lu & 1,1 & 0,7 & 0,7 & 0,5 & 0,5 & 0,7 & 0,6 & 0,5 & 0,8 & 0,9 & 0,4 & 1,0 & 1,0 & 0,9 \\
\hline$\Sigma$ ETR & 421,0 & 367,0 & 380,1 & 276,4 & 388,7 & 302,4 & 287,1 & 199,8 & 236,8 & 184,5 & 122,6 & 554,5 & 206,1 & 329,1 \\
\hline$(\mathrm{La} / \mathrm{Yb})$ & 7,8 & 9,4 & 11,6 & 10,1 & 15,8 & 11,4 & 10,7 & 9,6 & 6,5 & 4,6 & 6,1 & 11,4 & 4,7 & 9,1 \\
\hline $\mathbf{E u} / \mathbf{E u}^{*}$ & 0,3 & 0,3 & 0,3 & 0,3 & 0,3 & 0,3 & 0,3 & 0,3 & 0,3 & 0,3 & 0,5 & 0,2 & 0,2 & 0,2 \\
\hline$(\mathrm{La} / \mathrm{Sm})$ & 3,4 & 4,2 & 5,2 & 4,8 & 5,4 & 5,0 & 4,9 & 4,5 & 4,0 & 3,6 & 3,9 & 3,9 & 3,4 & 3,8 \\
\hline$(G d / Y b)^{N}$ & 1,7 & 1,6 & 1,5 & 1,4 & 1,5 & 1,4 & 1,4 & 1,4 & 1,0 & 1,0 & 1,2 & 1,9 & 1,0 & 1,7 \\
\hline
\end{tabular}

Considerando a assinatura geoquímica alcalina e sua relação com ambientes tectônicos pós-orogênicos/pós-colisionais, foram utilizados diferentes diagramas objetivando definir a afinidade geoquímica do Stock Flores com granitos tipo-A, conforme proposição inicialmente apresentada por Loiselle \& Wones (1979) e depois amplamente discutida e/ou redefinida na literatura sobre o tema.

A partir de critérios propostos por Nardi \& Bitencourt (2009) para a definição de granitos tipo-A, tais como: $\left(\mathrm{NaO}+\mathrm{K}_{2} \mathrm{O}\right)$ e $\left(\mathrm{FeO}_{\mathrm{T}} / \mathrm{FeO}_{\mathrm{T}}+\mathrm{MgO}\right)$ em rocha total, respectivamente igual ou maior que $9 \%$ e 0,$9 ;\left(10^{4 *} \mathrm{Ga}\right) / \mathrm{Al}>2,6$ e $\mathrm{Ce}+\mathrm{Y}+\mathrm{Nb}+\mathrm{Zr}>340$ ppm; e afinidade com granitos intraplacas no diagrama de Pearce et al. (1984), foi possível classificar o Stock Flores como granito tipo-A. A distribuição das amostras do Stock Flores nos diagramas $\mathrm{FeO}_{\mathrm{T}} /\left(\mathrm{FeO}_{\mathrm{T}}+\mathrm{MgO}\right)$ versus $\left[\left(\mathrm{Na}_{2} \mathrm{O} / 62+\left(\mathrm{K}_{2} \mathrm{O} / 94\right] /\right.\right.$ $\left.\mathrm{Al}_{2} \mathrm{O}_{3} / 102\right)$ e $\mathrm{Ga} /\left(\mathrm{Al}_{2} \mathrm{O}_{3}{ }^{*} 0,52\right)$ versus $(\mathrm{Zr}+\mathrm{Y}+\mathrm{Ce}+\mathrm{Nb})$ mostra uma clara afinidade com os granitos tipo-A (Fig.11A, B).

Dall'Agnol \& Oliveira (2007) propuseram os diagramas $\mathrm{FeO}_{\mathrm{T}} /\left(\mathrm{FeO}_{\mathrm{T}}+\mathrm{MgO}\right)$ versus $\mathrm{Al}_{2} \mathrm{O}_{3}$ e $\mathrm{FeO}_{\mathrm{T}} /$ $\left(\mathrm{FeO}_{\mathrm{T}}+\mathrm{MgO}\right)$ versus $\mathrm{Al}_{2} \mathrm{O}_{3} /\left(\mathrm{K}_{2} \mathrm{O} / \mathrm{Na}_{2} \mathrm{O}\right)$ para a distinção entre granitos tipo-A oxidado ou tipo-A reduzido. A utilização desses diagramas para as rochas do Stock Flores mostra uma afinidade com os 
granitos tipo-A oxidados (Fig. 11C, D).
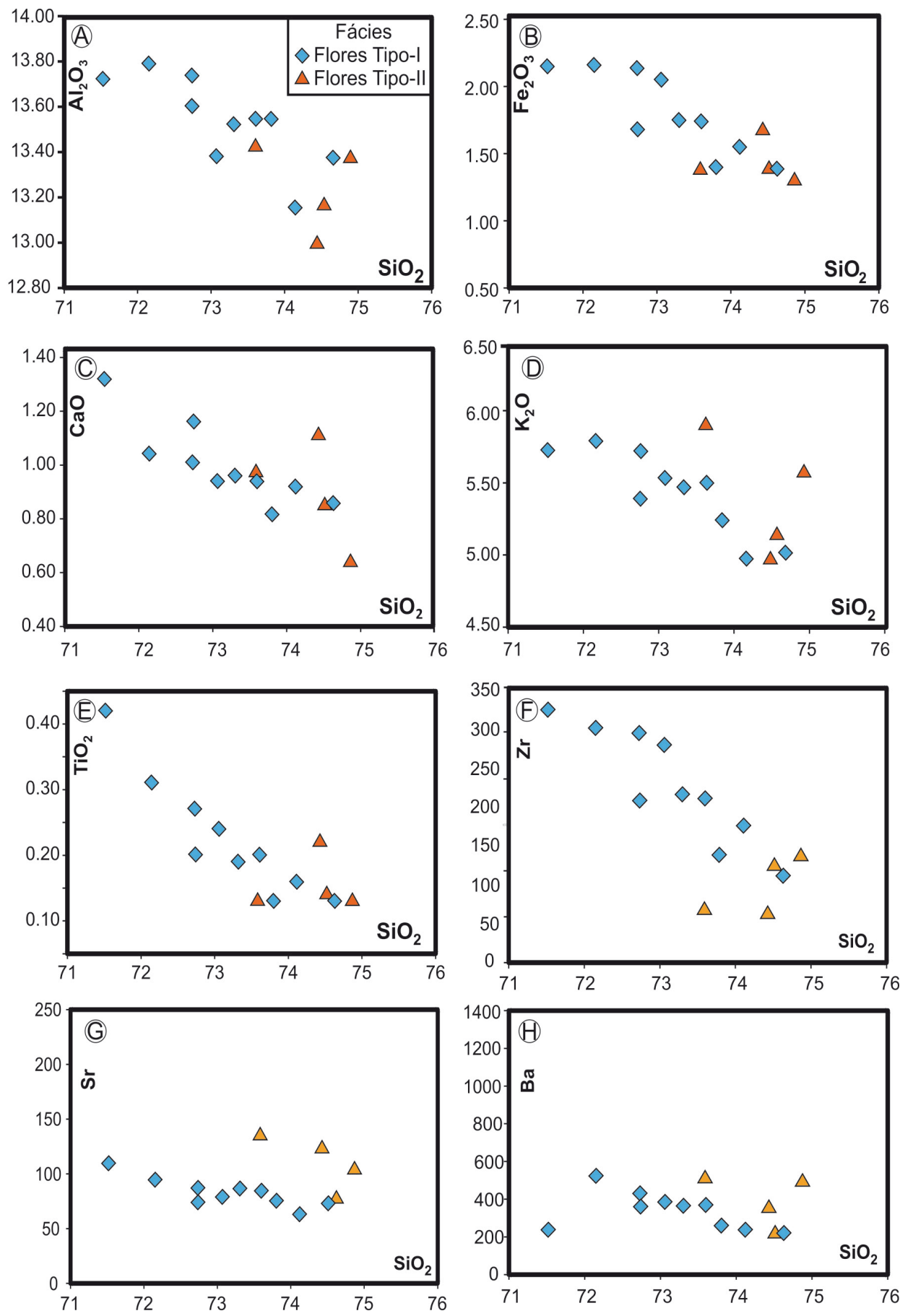

Figura 7. Diagramas tipo Harker exibindo predominantemente tendência negativa para alguns dos elementos químicos analisados. A) $\mathrm{Al}_{2} \mathrm{O}_{3} \times \mathrm{SiO}_{3}$; B) $\mathrm{Fe}_{2} \mathrm{O}_{3} \times \mathrm{SiO}_{3}$; C) $\mathrm{CaO} \times \mathrm{SiO}_{3}$ D) $\mathrm{K}_{2} \mathrm{O} \times \mathrm{SiO}_{3}$; E) $\mathrm{TiO}_{2} \times \mathrm{SiO}_{3}$; F) $\mathrm{Zr} \mathrm{x} \mathrm{SiO}_{3}$; G) $\mathrm{Sr}_{\mathrm{S} \mathrm{SiO}}$; H) $\mathrm{Ba} \times \mathrm{SiO}_{3}$.

Figure 7. Diagrams type Harker exhibiting predominantly negative trend for the some chemical elements analised. A) $\mathrm{Al}_{2} \mathrm{O}_{3} \times \mathrm{SiO}_{3^{3}}$ B) $\mathrm{Fe}_{2} \mathrm{O}_{3} \times \mathrm{SiO}_{3}$;C) $\mathrm{CaO} \times \mathrm{SiO}_{3}$ D) $\mathrm{K}_{2} \mathrm{O} \times \mathrm{SiO}_{3}$; E) $\mathrm{TiO}_{2} \times \mathrm{SiO}_{3}$; F) $\mathrm{Zr} \times \mathrm{SiO}_{3}$; G) $\mathrm{Sr} \times \mathrm{SiO}_{3}$; H) $\mathrm{Ba}_{2} \mathrm{SiO}_{3}$.

Os geotermômetros que envolvem saturação em $\mathrm{P}_{2} \mathrm{O}_{5}$ (Watson \& Harrison, 1984) e $\mathrm{Zr}$ (Watson \& Harrison, 1983) foram utilizados para se inferir a possível temperatura relativa ao liquidus do magma do Stock Flores, considerando que apatita e zircão são as fases minerais mais precoces na sua sequência de cristalização (ver discussão mais adiante). Os diagramas $\mathrm{P}_{2} \mathrm{O}_{5}$ versus $\mathrm{SiO}_{2}$ e $\mathrm{Zr}$ versus $(\mathrm{Na}+\mathrm{K}+2 \mathrm{Ca}) / \mathrm{Al}$ Si (Fig. 12C, D) indicam então temperaturas na faixa de $750^{\circ} \mathrm{C}$ a $840^{\circ} \mathrm{C}$ para o $\mathrm{li}$ quidus (início da cristalização de apatita e zircão).

As condições de fugacidade de oxigênio relativas a evolução do magma dos monzogranitos do Stock Flores é aqui inferida principalmente com base nos parâmetros mineralógicos de suas rochas. A presença da paragênese mineral titanita+magnetita+quartzo, primária e em equilíbrio, sugere $\mathrm{fO}_{2}$ moderada a alta (Wones, 1989). 
Esta indicação é também em parte corroborada pela presença de hematita normativa em todas as amostras do Stock, além de razões $\mathrm{Fe} /(\mathrm{Fe}+\mathrm{Mg})>7$ para a biotita indicando $\mathrm{fO}_{2}$ na transição dos tampões QFM/NNO (Galindo et al., 2012).
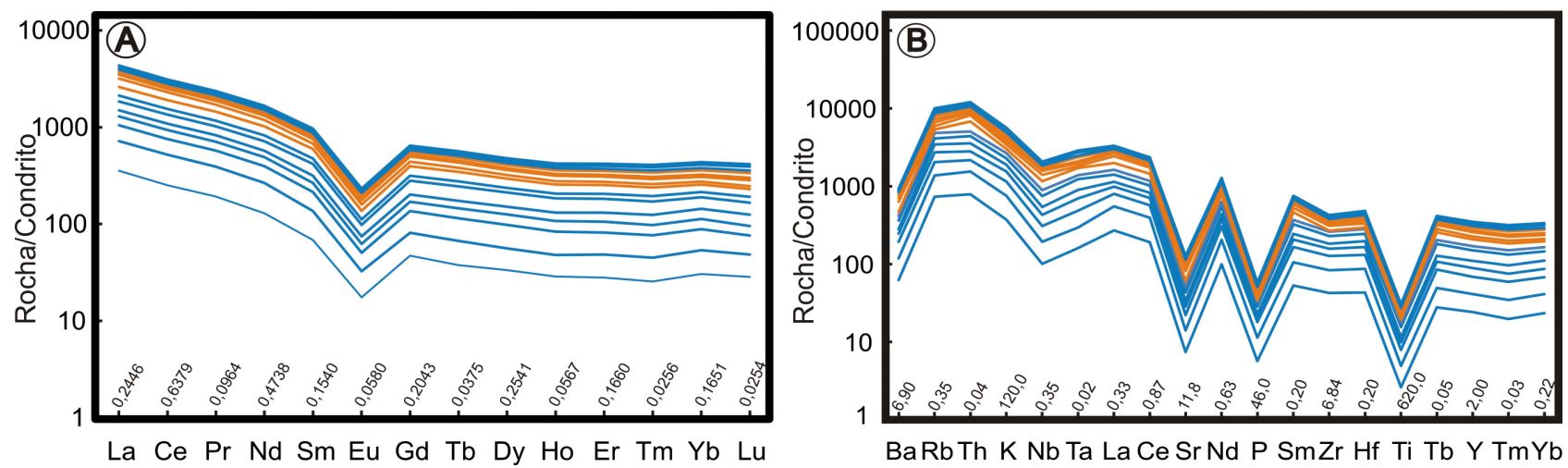

Figura 8. Diagramas de diferentes elementos terras raras e traços, para as rochas do Stock Flores. Fácies Tipo-I (Linhas laranjas); Fácies Tipo-II (Linhas azuis). A) Espectro de ETR com valores normalizados em relação ao condrito de Evensen et al. (1978); B) Espectro de multielementos com valores normalizados em relação ao condrito de Thompson (1982).

Figure 8. Diagrams of different rare earths and trace elements, to the rocks of the Flores stock. Facies type-I (oranges lines); Facies Type-II (blue lines). .A) REE spectrum with normalized values relative to the Chondrite Evensen et al. (1978); B) Multi-element spectrum with normalized values relative to Chondrite Thompson (1982).

\section{Discussão dos resultados}

A ausência de estruturas dúcteis e presença apenas de estruturas frágeis (N-NW e N-NE), associada ao fato da intrusão cortar a foliação regional (NNE-SSW), assim como a idade de $553 \pm 4 \mathrm{Ma}$, U-Pb em zircão (Souza et al., 2015), evidenciam o caráter tardi a pós-tectônico do alojamento do Sto$c k$ Flores dentro do contexto da orogênese Brasilina/Panafricana na Província Borborema.

A ocorrência localizada das rochas da fácies Tipo II, na porção S/SE, sempre associadas a enclaves máficos, inclusive com feições de mixing $e$ mingling, são parâmetros indicativos que, em parte, essas rochas são produtos de hibridização. Dessa forma, essa porção arrasada do Stock Flores é possivelmente resultado de um processo erosional mais efetivo na área, em função da maior quantidade de enclaves máficos.

Schlieren elipsoidais são estruturas pouco observadas em granitos evoluídos, como é o caso do Stock Flores, podendo fornecer informações valiosas acerca das dinâmicas internas da câmara magmática a época da colocação do plutão, desse modo os schlieren em granitos vêm sendo objeto de intenso debate por vários pesquisadores. Dentre os vários modelos que explicam a gênese desses tipos de schlieren (Smith, 1975; Barrière, 1976, 1981; Irvine, 1980; Barbarin, 2005; Barbey, 2009; Farner \& Lee, 2013) destaca-se, neste trabalho, o modelo proposto por Weinberg et al. (2001). Para aqueles autores, os schlieren elipsoidais são formados por convecção magmática em função da desestabilização térmica causada por plumas ter- mais (Fig. 13A), estas por sua vez, surgem em função das diferentes densidades entre dois ou mais fluidos (Wilson, 1963; Griffiths, 1986; Campbell et al., 1989; Weinberg et al., 2001).

De acordo com o exposto, o presente trabalho propõe para a gênese dos schlieren elipsoidais do Stock Flores um processo de desestabilização térmica, que evoluiu para um fluxo magmático diferenciado (pluma termal), culminando em um processo convectivo dentro da câmara (Fig.13B).

Três hipóteses, similares àquelas de Weinberg et al. (2001) para o pluton de Tavares (PB), são aqui proposta para explicar o fator desencadeante dessa pluma térmica: i) uma série de magmas graníticos quentes liberados diretamente da fonte; ii) uma série de magmas graníticos aquecidos por uma intrusão magmática diorítica, ou; iii) assimilação de enclaves máficos.

$\mathrm{Na}$ área de estudo não foram encontradas evidências diretas das duas primeiras hipóteses. Assim, a terceira hipótese parece mais provável, levando em consideração que o fácies Tipo II encerra vários enclaves máficos, que podem ter sido a fonte de calor necessário para causar diferenças substanciais de densidades na câmara magmática, dando origem às plumas.

Apesar da pequena dimensão, o corpo estudado exibe várias estruturas que denotam o caráter dinâmico do fluxo magmático dentro da câmara, evidenciando que a homogeneidade durante a cristalização é aparente. Isso ocorre porque o registro desses processos é frequentemente, sobreposto por outros processos durante a evolução do granito. 
As relações mineralógicas e microtexturais observadas (relações de inclusão, tipos de contatos entre os minerais, morfologia dos cristais, etc.), são indicativas de sequência de cristalização e de alguns dos processos magmáticos que ocorrem no decorrer da cristalização.

No estágio magmático, as primeiras fases a cristalizarem foram zircão, apatita, e allanita, seguindo-se a cristalização da titanita e minerais opacos primários. A próxima fase a cristalizar-se, foi mais hidratada representada pela biotita, su-
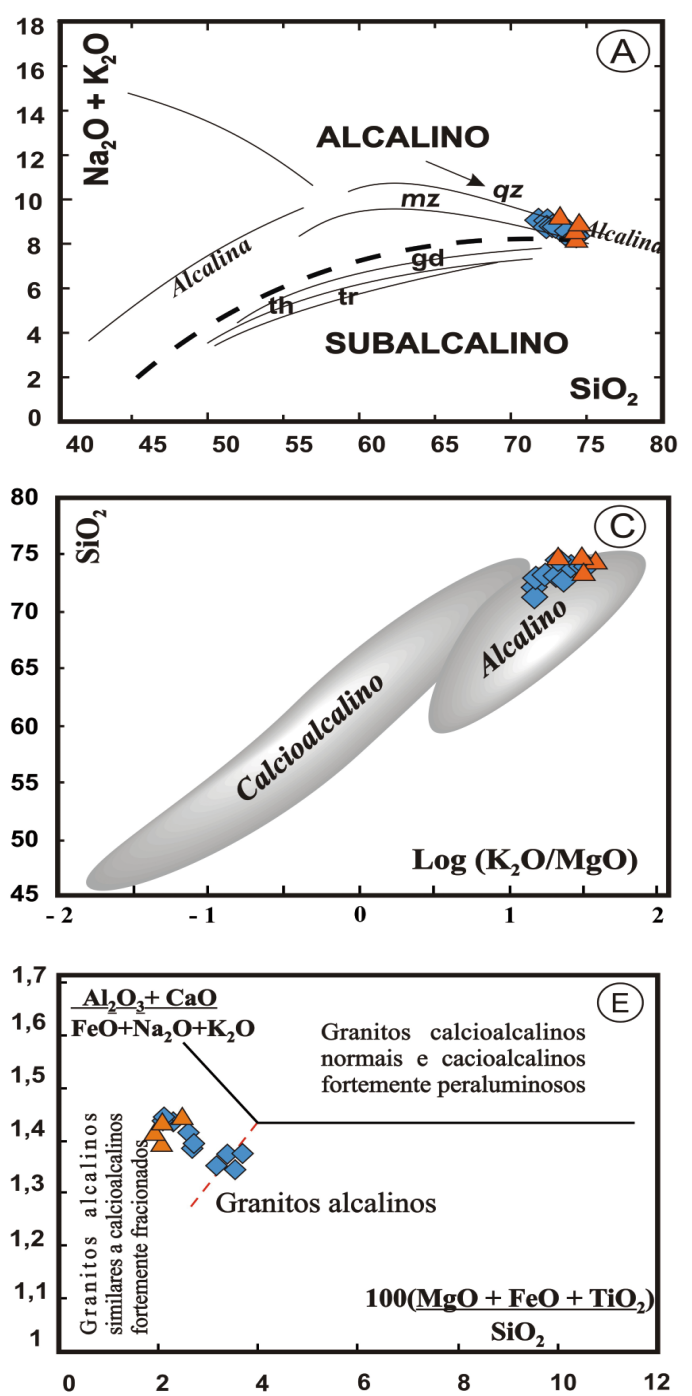

gerindo o aumento da $\mathrm{fH}_{2} \mathrm{O}$, que foi seguida pela cristalização dos feldspatos e do quartzo (possivelmente com uma fase um pouco mais precoce de plagioclásio), formando o arcabouço geral da rocha. 0 estágio tardi-magmático é marcado pela alteração/desestabilização da biotita para clorita, muscovita e opacos, do plagioclásio para saussurita e carbonatos, bem como a cristalização tardia da fluorita. Estas alterações podem estar associadas a efeitos de fluídos hidrotermais tardi-magmáticos, onde a temperatura é abaixo da curva do solidus.
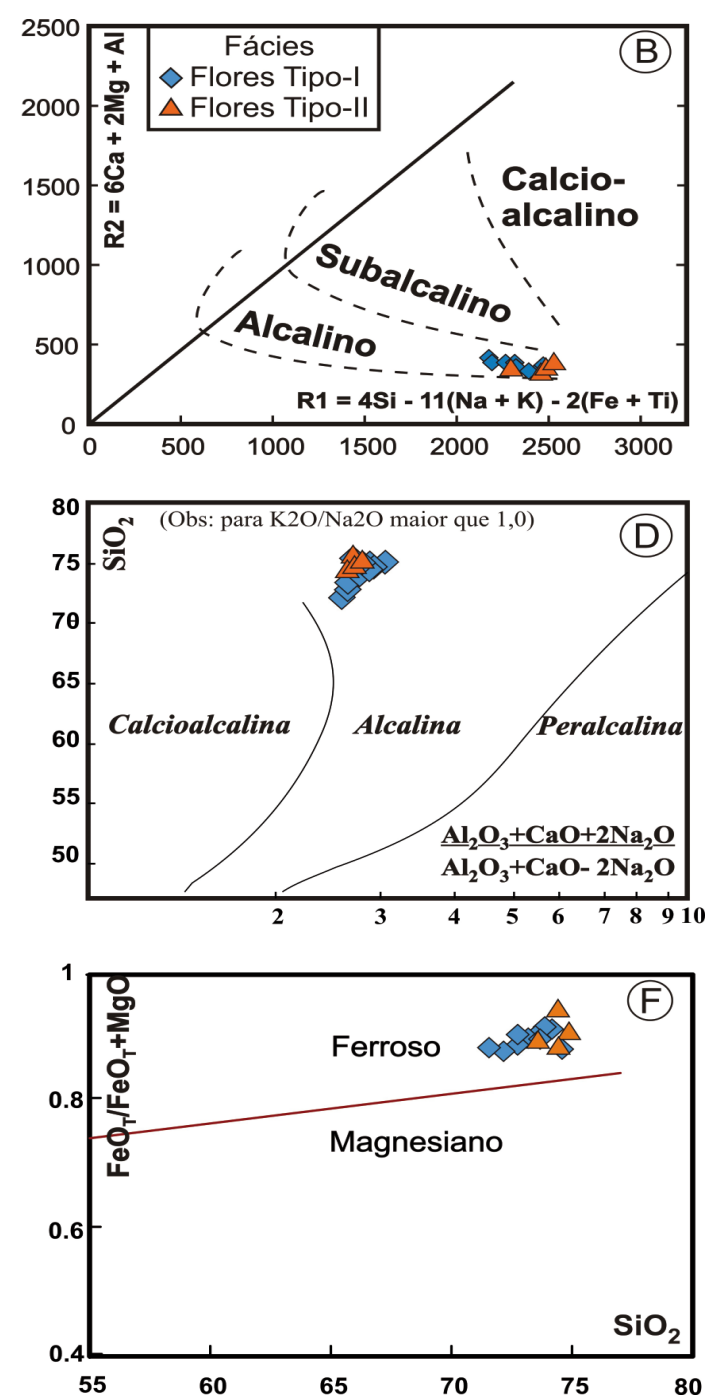

Figura 9. Diagramas utilizados na definição de séries magmáticas do Stock Flores, segundo vários autores. A) Total de álcalis versus sílica (Lameyre, 1987), linha tracejada, delimitando campos alcalinos e subacalino, segundo Miyashiro (1978); B) R1 versus R2 (De La Roche et al.,1980); C) Rogers \& Greenberg (1981); D) Wright (1969) com abscissas diferenciadas; E) Sylvester (1989); F) Frost et al. (2001).

Figure 9. Diagrams used in magmatic series definition of the Flores stock, according to several authors. A) Total alkalis versus silica (Lameyre, 1987), the dashed line delimiting fields alkali and subalkaline according Miyashiro (1978); B) R1 versus R2 (De La Roche et al., 1980); C) Rogers \& Greenberg (1981); D) Wright (1969) with different abscissas; E) Sylvester (1989); F) Frost et al. (2001).

A ocorrência de cristais zonados de allanita e plagioclásio sugere que a cristalização fracionada foi um processo relevante na evolução do magma que deu origem ao Stock Flores. A presença de cristais precoces de titanita+magnetita+quartzo, em equilíbrio, é indicativa de $\mathrm{fO}_{2}$ de moderada a

alta, acima do tampão FMQ (Wones, 1989). A cristalização de mineral hidratado (biotita) no início da diferenciação magmática é indicativa de que o magma gerador do Stock Flores era subsaturado em água. A alta $\mathrm{fH}_{2} \mathrm{O}$ é corroborada pela presença de texturas pertíticas e mirmequíticas, visto que 
essas são recorrentes em sistemas graníticos hidratados (Winter, 2001). Estas mesmas texturas, com destaque para a mirmequítica, são indicativas da ocorrência de uma fase fluída aquosa tardia atuante no sistema (Yuguchi \& Nishiyama, 2007).
A presença de fluorita assinala a existência de conteúdo de voláteis no estágio subsolidus, sendo este mineral relativamente comum em granitos tipo-A (Collins et al., 1982; Pitcher, 1983; Costi et al., 2002; Kaur et al., 2012).
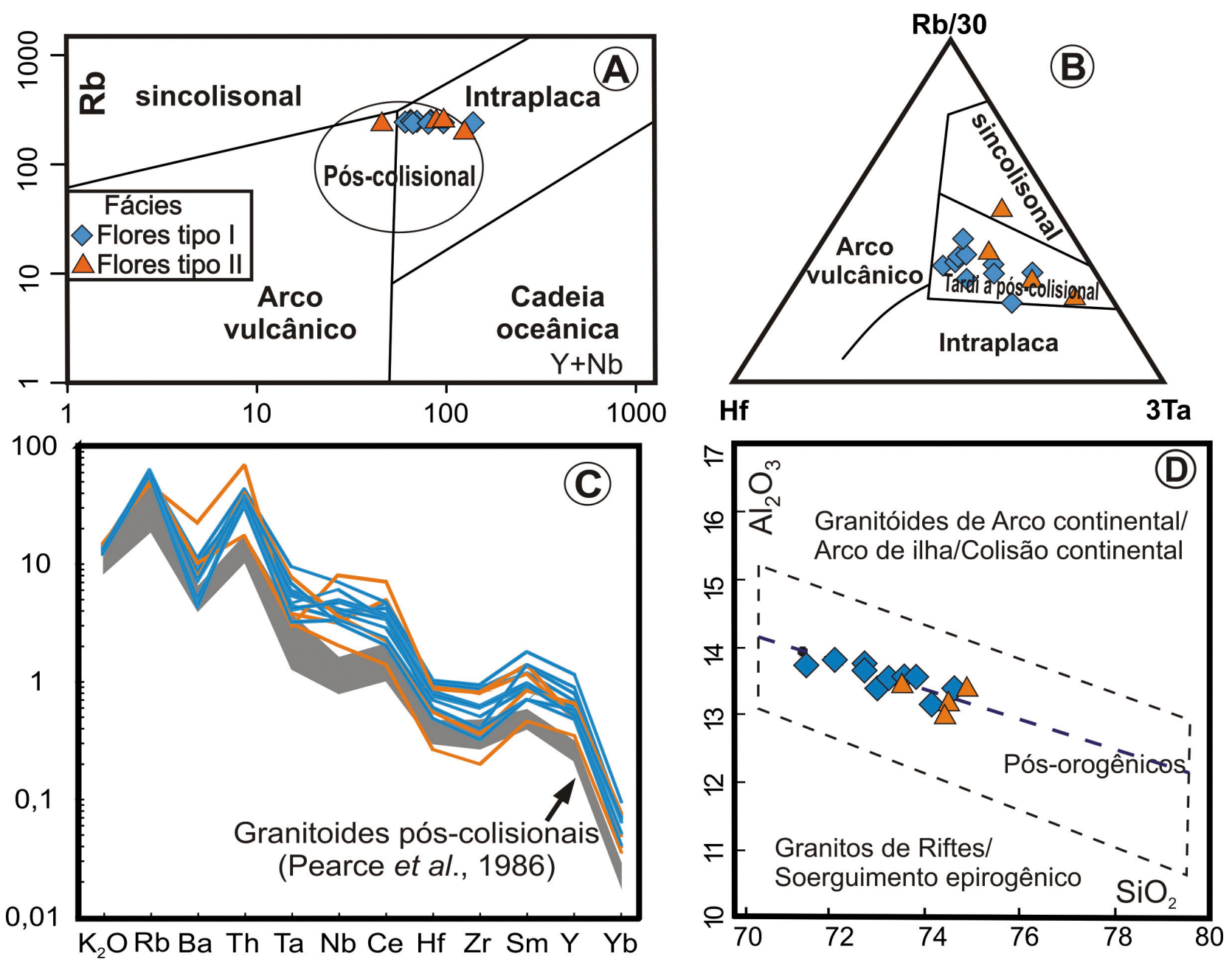

Figura 10. Diagramas utilizados na definição de ambientes tectônicos para as rochas do Stock Flores. A) Rb versus Y+Nb (Pearce, 1996); B) Rb/30- Hf - Ta*3 (Harris et al., 1986); C) Diagrama multielementos com envelope para granitos pós-colisionais (Pearce et al., 1984); D) $\mathrm{Al}_{2} \mathrm{O}_{3}$ versus $\mathrm{SIO}_{2}$ (Maniar \& Piccoli, 1989).

Figure 10. Diagrams used in the definition of tectonic environments for rocks of the Flores stock. A) Rb versus $Y+N b$ (Pearce, 1996); B) Rb/30- $\mathrm{Hf}-\mathrm{Ta} * 3$ (Harris et al., 1986); C) Diagram multi-element with envelope for post-collisional granites (Pearce et al., 1984); D) Al2O3 versus SiO2 (Maniar \& Piccoli, 1989).

O caráter peraluminoso das rochas do Stock Flores está relacionado às baixas concentrações de $\mathrm{CaO}(0,64 \%-1,32 \%)$ e, não necessariamente, às altas concentrações de $\mathrm{Al}_{2} \mathrm{O}_{3}(12,99 \%$ - 13,79\%). Nos diagramas do tipo Harker as correlações observadas sugerem cogeneticidade entre as duas fácies do stock, tal qual sugerido pela petrografia. As correlações negativas exibidas pelos $\mathrm{Al}_{2} \mathrm{O}_{3}, \mathrm{Fe}_{2} \mathrm{O}_{3}$, $\mathrm{CaO}, \mathrm{K}_{2} \mathrm{O}$ e $\mathrm{Zr}$ estão relacionadas ao fracionamento de biotita, minerais opacos, zircão, plagioclásio e $\mathrm{K}$-feldspato durante a evolução dessas rochas. $\mathrm{O} \mathrm{Sr}$ e o Ba apresentam dispersão com leve tendência a correlação negativa, sugerindo que esses elementos tiveram uma distribuição quase homogênea durante o processo de cristalização dos feldspatos ao longo da evolução magmática.

O conteúdo total de ETR nas amostras analisadas, situa-se entre 122,6 ppm e 554,5 ppm, com espectros subpararelos entre si, que sugerem cogeneticidade entre as amostras das duas fácies do Stock Flores. 0 enriquecimento relativo de ETRL em relação aos ETRP, característico de rochas crustais, ocorre devido à incorporação dos ETR de maiores raios iônicos na fração líquida, distribuindo os ETRs dominantemente nos minerais acessórios (Figueiredo, 1985). Neste caso, o empobrecimento em ETRP sugere que tais elementos foram incorporados ao zircão durante o fracionamento do magma do Stock Flores. Outro fator em destaque é a marcante anomalia negativa de európio 
indicativa do fracionamento dos feldspatos durante a evolução magmática. Este espectro dos ETRs,
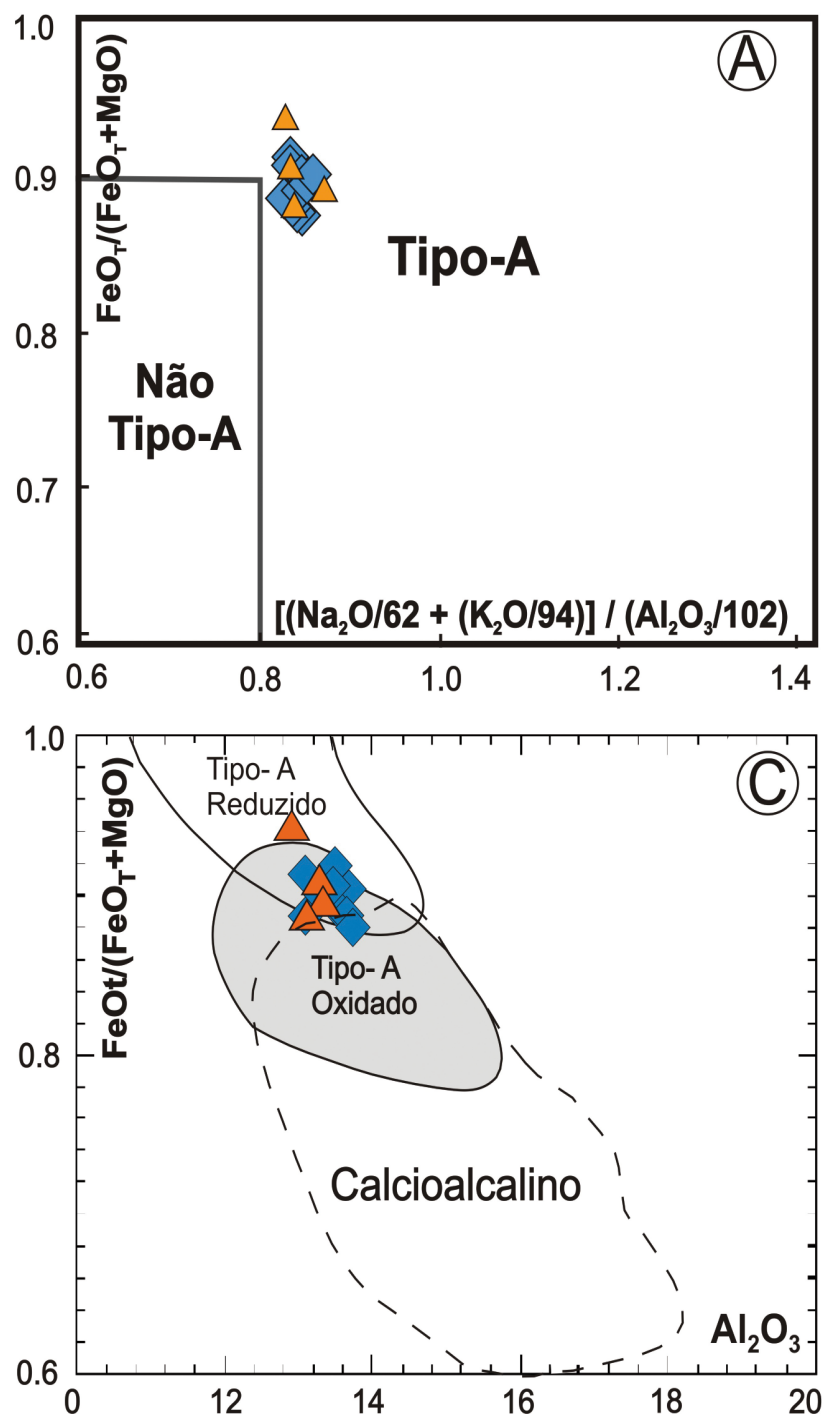

assemelhando-se ao padrão tipo andorinha, é característico de granitos tipo-A.
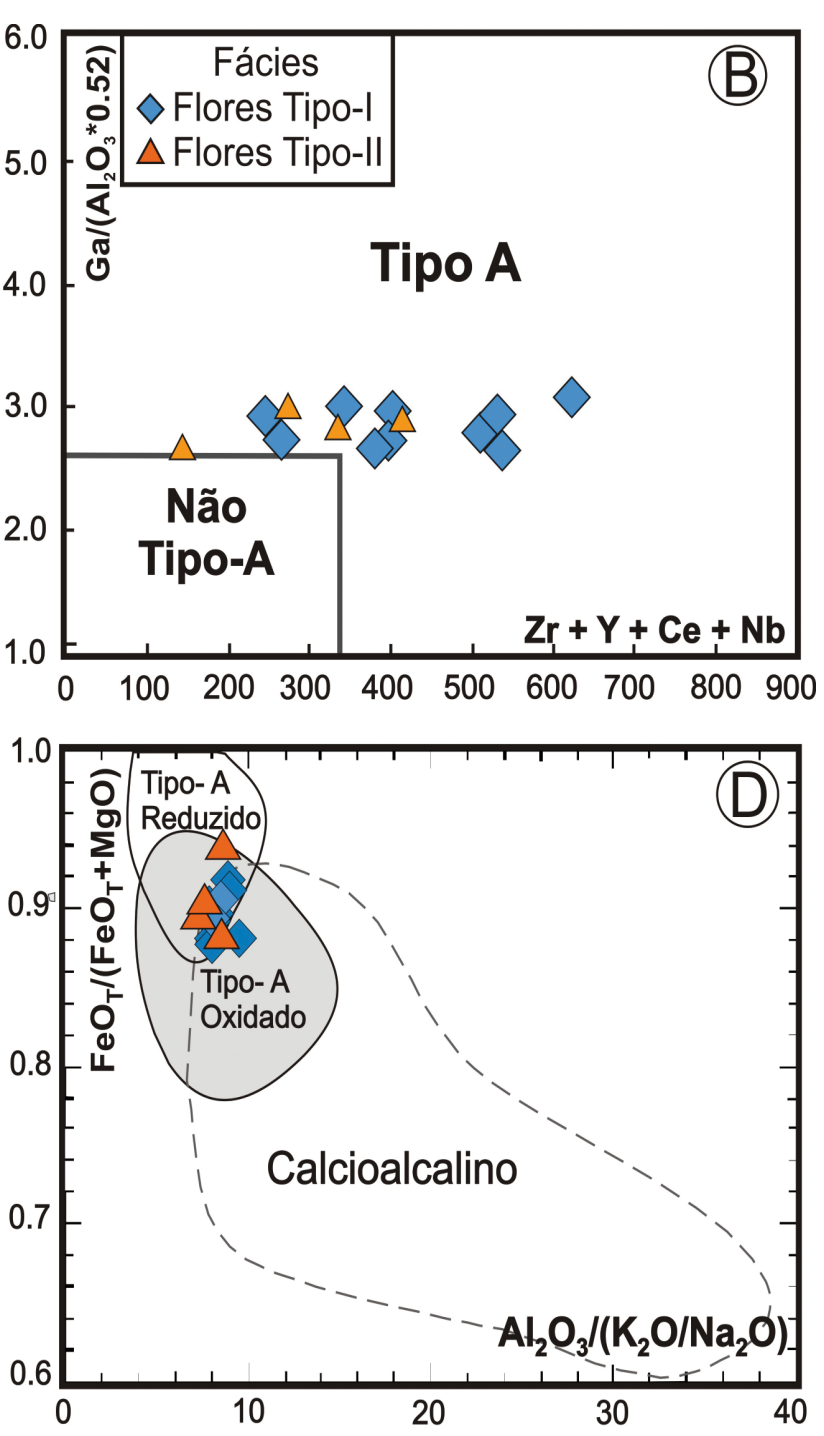

Figura 11. Diagramas para classificação de tipologia de granitos. A) Eixos $\mathrm{FeO}_{\mathrm{T}} /\left(\mathrm{FeO}_{\mathrm{T}}+\mathrm{MgO}\right)$ versus $\left[\left(\mathrm{Na}_{2} \mathrm{O} / 62+\left(\mathrm{K}_{2} \mathrm{O} / 94\right)\right] /\right.$ $\left(\mathrm{Al}_{2} \mathrm{O}_{3} / 102\right)$; $\left.\mathrm{B}\right)$ Eixos $\mathrm{Ga} /\left(\mathrm{Al}_{2} \mathrm{O}_{3}{ }^{*} 0,52\right)$ versus $\left.(\mathrm{Zr}+\mathrm{Y}+\mathrm{Ce}+\mathrm{Nb}) ; \mathrm{C}\right) \mathrm{FeO}_{\mathrm{T}} /\left(\mathrm{FeO}_{\mathrm{T}}+\mathrm{MgO}\right)$ versus $\left.\mathrm{Al}_{2} \mathrm{O}_{3} ; \mathrm{D}\right) \mathrm{FeO}_{\mathrm{T}} /\left(\mathrm{FeO} \mathrm{T}_{\mathrm{T}}+\mathrm{MgO}\right)$ versus $\mathrm{Al}_{2} \mathrm{O}_{3} /\left(\mathrm{K}_{2} \mathrm{O} / \mathrm{Na}_{2} \mathrm{O}\right)$.

Figure 11. Diagrams of classification for typology of granites. A) Axes $\mathrm{FeO}_{T} /(\mathrm{FeO}+\mathrm{MgO})$ versus $\left[\left(\mathrm{Na}_{2} \mathrm{O} / 62+\left(\mathrm{K}_{2} \mathrm{O} / 94\right)\right] /\left(\mathrm{Al}_{2} \mathrm{O}_{3} / 102\right)\right.$;

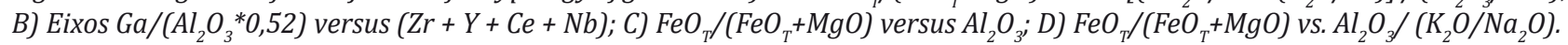

0 espectro do diagrama multielementos evidenciou anomalias negativas para $\mathrm{Nb}, \mathrm{Sr}, \mathrm{P}$ e $\mathrm{Ti}$, sugerindo fracionamento de plagioclásio, apatita e titanita. 0 padrão espectral geral da curva com inclinação negativa Ba-Yb sugere que o fracionamento magmático não sofreu mudanças significativas de condições de cristalização durante sua evolução, sugerindo novamente cogeneticidade entre as amostras das duas fácies do stock.

Nos diagramas discriminantes de séries e associações magmáticas as rochas do Stock Flores exibiram sistematicamente assinatura alcalina. No diagrama de Sylvester (1989) a transição das amostras do campo alcalino para o subdomínio dos granitos alcalinos similares a granitos calcioalcalinos fortemente fracionados, é explicada como o reflexo de uma química calcioalcalina de alto potássio de rochas fontes, sendo essas rochas associadas com fusão da crosta média/inferior. 0 caráter alcalino das rochas do Stock Flores é coerente com as relações entre o stock e suas rochas encaixantes, uma vez que a presumível fonte do magma progenitor são rochas crustais granodioríticas de caráter calcioalcalino potássico presentes no Complexo Caicó (Souza et al., 2007), dessa forma uma baixa taxa de fusão dessas rochas originariam magmas bastante evoluídos de assinatura alcalina (Sylvester, 1989).

0 enquadramento do Stock Flores como representante de um magmatismo granítico tipo-A no âmbito do Domínio Rio Piranhas-Seridó é embasado tanto em suas características de campo (intrusão discordante em relação a tectônica regional 
Brasiliana/Panafricana), petrográficas (monzogranito hololeucocrático), quanto geoquímicas (conforme observado nos diagramas propostos por Dall'Agnol \& Oliveira, 2007; Nardi \& Bitencourt, 2009). No diagrama de Frost et al. (2001) as rochas que plotam no campo ferroso, caso das amostras do Stock Flores, são equiparadas aos granitos tipo-A, associados a fusão de crosta e usualmente relacionados com ambientes tectônicos pós-colisionais. Adicionalmente, o caráter tipo-A oxidado das rochas do Stock Flores está associado com as rochas progenitoras do magma as quais são, geralmente, rochas ígneas quartzo-feldspáticas de crosta inferior fundidas em condições oxidantes. Ressalta-se ainda que a presença de magnetita modal e hematita normativa nas rochas do Stock Flores coaduna-se com este caráter de tipo-A oxidado.

A temperatura inicial deduzida para o magma progenitor do Stock Flores (liquidus) com base nos geotermômetros $\mathrm{P}_{2} \mathrm{O}_{5}$ versus $\mathrm{SiO}_{2}$ (Watson \& Harrison, 1984) e o método de saturação em $\mathrm{Zr}$ (Watson \& Harrison, 1983), situa-se na faixa de $750^{\circ} \mathrm{C}$ a $860^{\circ} \mathrm{C}$, considerando que apatita e zircão são fases magmáticas precoces na história evolutiva do Stock Flores. Essa estimativa é coerente com as temperaturas de magmas tipo-A determinadas experimentalmente, em geral $\mathrm{T}>800^{\circ} \mathrm{C}$ (Clemens et al., 1986; Scaillet \& Pichavant, 1999). Por outro lado, as temperaturas relativas ao solidus, indicada pelos sistemas normativo Qz-Ab-Or, situam-se na faixa de $680^{\circ} \mathrm{C}$, ou seja, bem próximas do eutético ternário granítico.
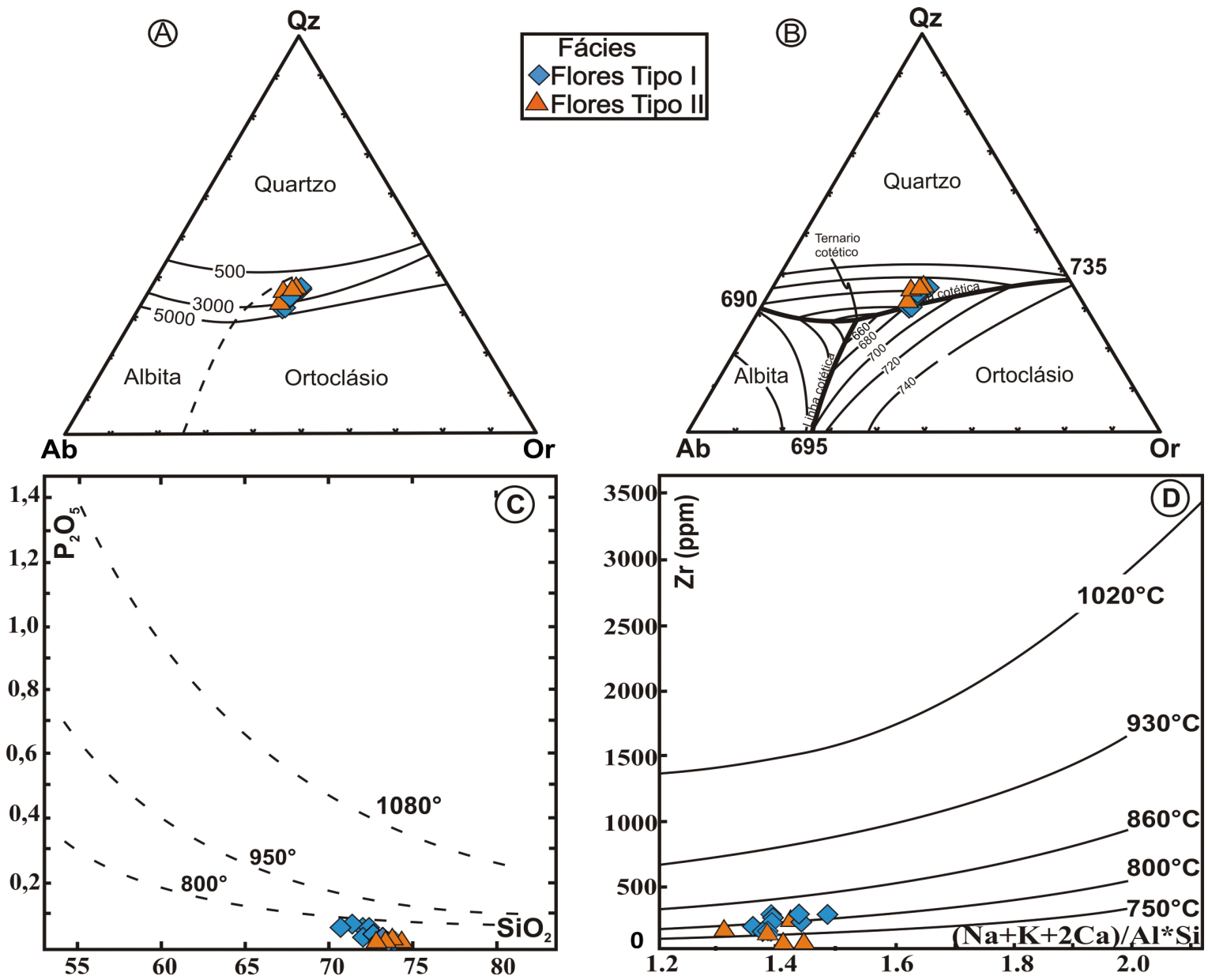

Figura 12. Diagramas para a obtenção das pressões e temperaturas das rochas do Stock Flores. A) Diagrama normativo para pressão (Tuttle \& Bowen, 1958) exibindo distribuição dos dados entre 3 a 5 kbar de pressão; B) Diagrama normativo para temperatura (Luth et al., 1964) ) exibindo distribuição dos dados na isoterma de $680^{\circ}$ C; C) Diagrama $\mathrm{P}_{2} \mathrm{O}_{5}$ versus $\mathrm{SiO}_{2}$ (Watson \& Harisson, 1984) com as isotermas que refletem as temperaturas de cristalização das apatitas; D) Diagrama Zr versus (Na+K+2Ca)/Al*Si (Watson \& Harrison, 1983) com as isotermas que refletem as temperaturas de cristalização dos zircões.

Figure 12. Diagram for obtaining the pressure and temperature of the rocks Flores stock. A) Normative diagram for pressure (Tuttle \& Bowen, 1958) showing data distribution between 3 and 5 kbar pressure; B) Normative diagram for temperature (Luth et al., 1964).) showing distribution of data in the isotherm $680^{\circ} \mathrm{C} ; \mathrm{C}$ ) Diagram $\mathrm{P}_{2} \mathrm{O}_{5}$ versus $\mathrm{SiO}_{2}$ (Watson \& Harrison, 1984) with the isotherms reflecting the crystallization temperatures of apatite; $\mathrm{D})$ versus $\mathrm{Zr}$ diagram $(\mathrm{Na}+\mathrm{K}+2 \mathrm{Ca}) / \mathrm{Al} * \mathrm{Si}(\mathrm{Watson} \& \mathrm{Harrison}$, 1983) with the isotherms reflecting the crystallization temperatures of the zircons. 
Com base em dados prévios (Maia, 2004), Nascimento et al. (2015) classificaram o Stock Flores, como pertencente a suíte Calcioalcalina de alto K Equigranular, entretanto os dados aqui apresentados nos permitem associá-lo com a suíte Alcalina dos referidos autores. Considerando que o Stock Flores encontra-se em um domínio geológico distinto da reconhecida suíte Alcalina de Nascimento et al. (2015), é possível resguardar algumas diferenças, destacando-se: i) petrograficamente as rochas da suíte Alcalina de Nascimento et al. (2015) são granitos alcalinos stricto sensu por apresentarem clinopiroxênio tipo aegirina augita, e o plagioclásio é albita com $\mathrm{An}_{0-9 \%}$, acarretando em composições nos campos dos quartzo álcali feldspato sienito, álcali feldspato granito e sienogranitos. Por seu lado, as rochas do Stock Flores são essencialmente monzogranitos hololeucocráticos com biotita < 5\% modal; ii) no contexto geoquímico as rochas da suíte Alcalina de Nascimento et al. (2015) são mais enriquecidas em $\mathrm{Al}_{2} \mathrm{O}_{3}, \mathrm{Na}_{2} \mathrm{O}, \mathrm{Ba}$ e $\mathrm{Sr}$, do que as rochas do Stock Flores, refletindo principalmente as composições albíticas dos plagioclásios, e mais empobrecidas em $\mathrm{Rb}$. Os teores de $\mathrm{K}_{2} \mathrm{O}$ são mais restrito no Stock Flores (entre 5-6\%) e com mais ampla variação nos demais alcalinos (3,5-7,5\%; fig. 14); iii) nas relações de campo os alcalinos (Nascimento et al. 2015) mostram uma íntima associação com zonas de cisalhamento, caracterizando-os como corpos sintectônicos a estas estruturas relacionadas a orogenia Brasiliana / Panafricana (Nascimento, 1998; Hollanda et al., 1999; Nascimento et al., 2000), enquanto o Sto$c k$ Flores não é associado a nenhuma zona de cisalhamento dúctil. As idades relatadas para a suíte alcalina situam-se entre 585-600 Ma mostrando o caráter sintectônico no contexto da orogenia Brasiliana / Panafricana, por sua vez, o Stock Flores com idade de 553 Ma (Souza et al., 2015) é tardi a pós-tectônico. Diante do exposto o presente trabalho sugere que o Stock Flores seja reclassificado como pertencente a suíte Alcalina de Nascimento et al. (2015).

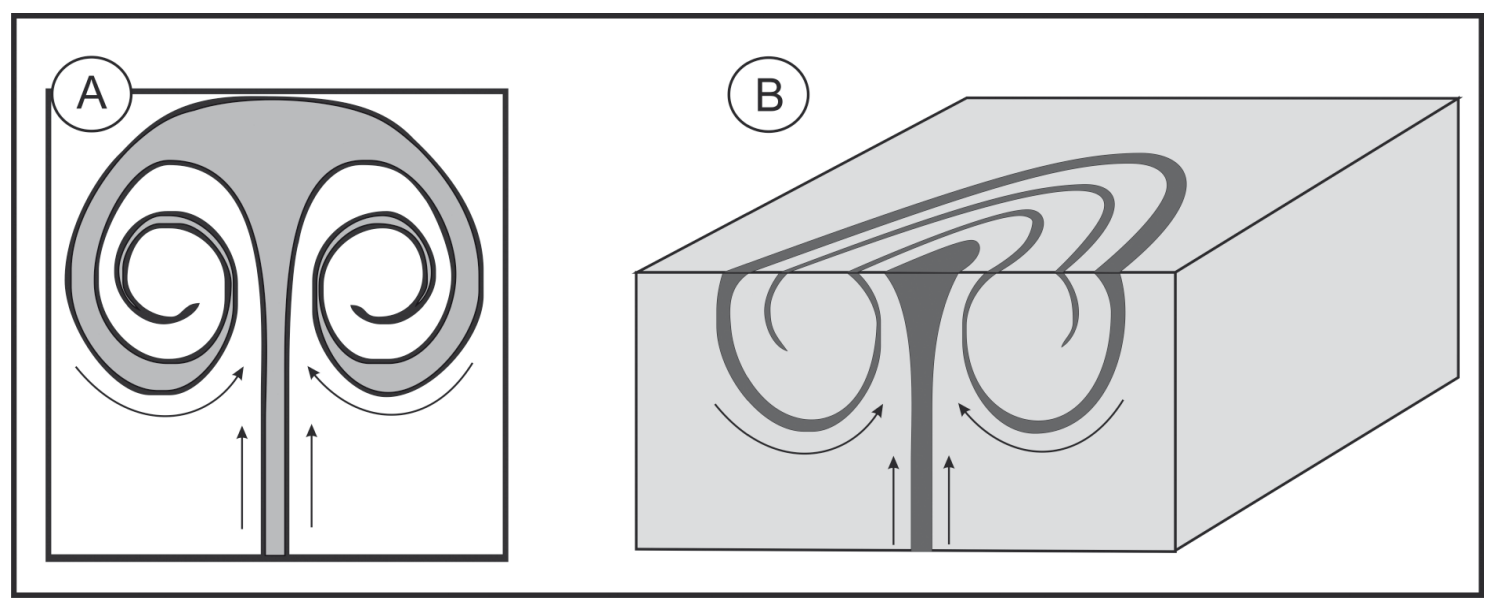

Figura 13. Modelo para a gênese dos schlieren elipsoidais. A) Modelo de convecção magmática causada por pluma magmática (modificado de Weinberg et al., 2001); B) Bloco diagrama idealizado para as estruturas elipsoidais do Stock Flores.

Figure 13. Model for the genesis of the ellipsoidal schlieren. A) Magmatic convection model caused by magmatic plume (modified Weinberg et al., 2001); B) Block diagram idealized for the ellipsoidal structures of the Flores stock.

\section{Conclusões}

O Stock Flores (553 \pm 4 Ma; Souza et al., 2015) intrude rochas gnáissicas paleoproterozoicas e suas feições de campo o definem como um stock a tardi a pós-tectônico no contexto da orogênese Brasiliana / Panafricana. Compreende essencialmente monzogranitos hololeucocráticos equigranulares, com biotita como mineral máfico dominante. Contém enclaves de rochas dioríticas que exibem evidências de coexistência e mistura parcial de magmas além de enclaves do tipo schlieren elipsoidais indicativos de processos de desequilíbrio térmico/gravitacional durante a cristalização e evolução do magma. Este desequilíbrio é relacio- nado a plumas térmicas e/ou correntes de convecção na câmara magmática. Desse modo, a história evolutiva do magma do Stock Flores não é marcada por uma cristalização em equilíbrio continua e homogênea, mas sim por uma soma de processos que se alternam na câmara magmática resultando em diferentes estruturas observáveis.

Os processos de carbonatação e saussuritização nos plagioclásios indicam a atuação de fluídos tardi-magmáticos com $f \mathrm{CO}_{2}$ e $f \mathrm{H}_{2} \mathrm{O}$. Tais fluídos colaboraram ainda para a desestabilização da biotita para clorita+opacos, podendo ainda ter contribuído para o desenvolvimento das texturas mirmequíticas, pertíticas e granofíricas, esta última típica de granitos hipoabissais. As condições 
de $\mathrm{fO}_{2}$ podem ser inferidas de moderadas a altas com base na presença da paragênese mineral
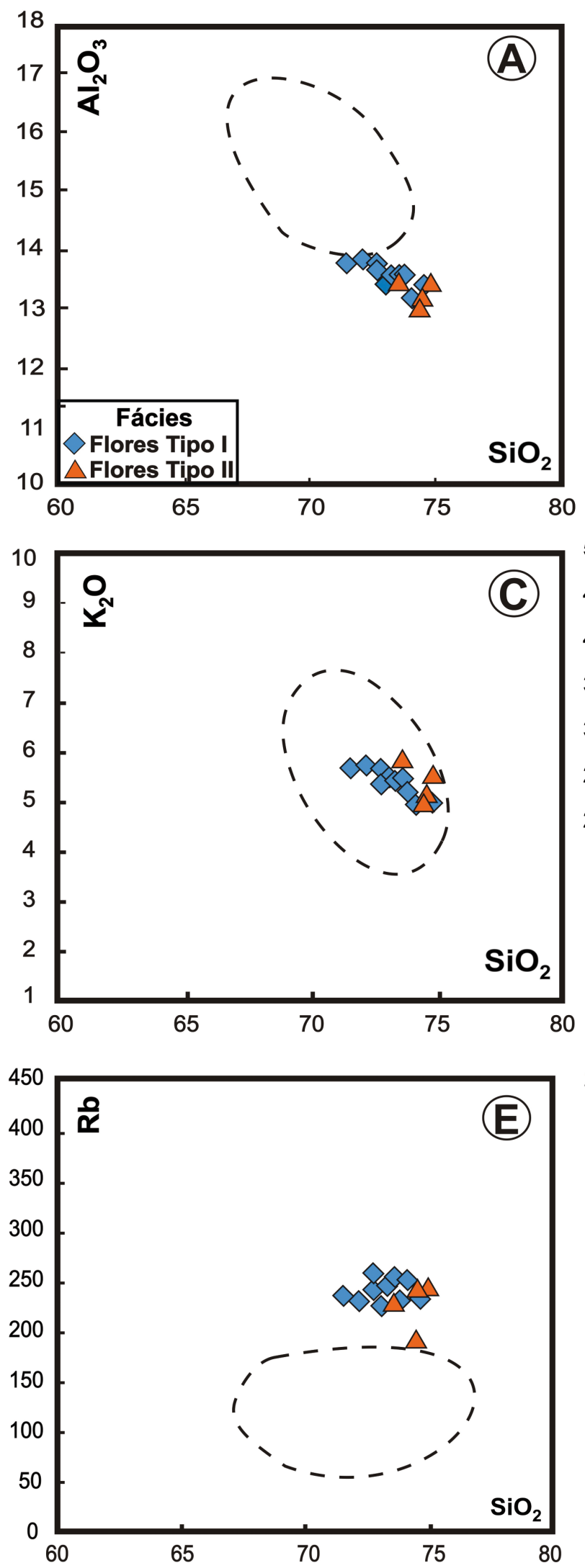

titanita+magnetita+quartzo (Wones, 1989).
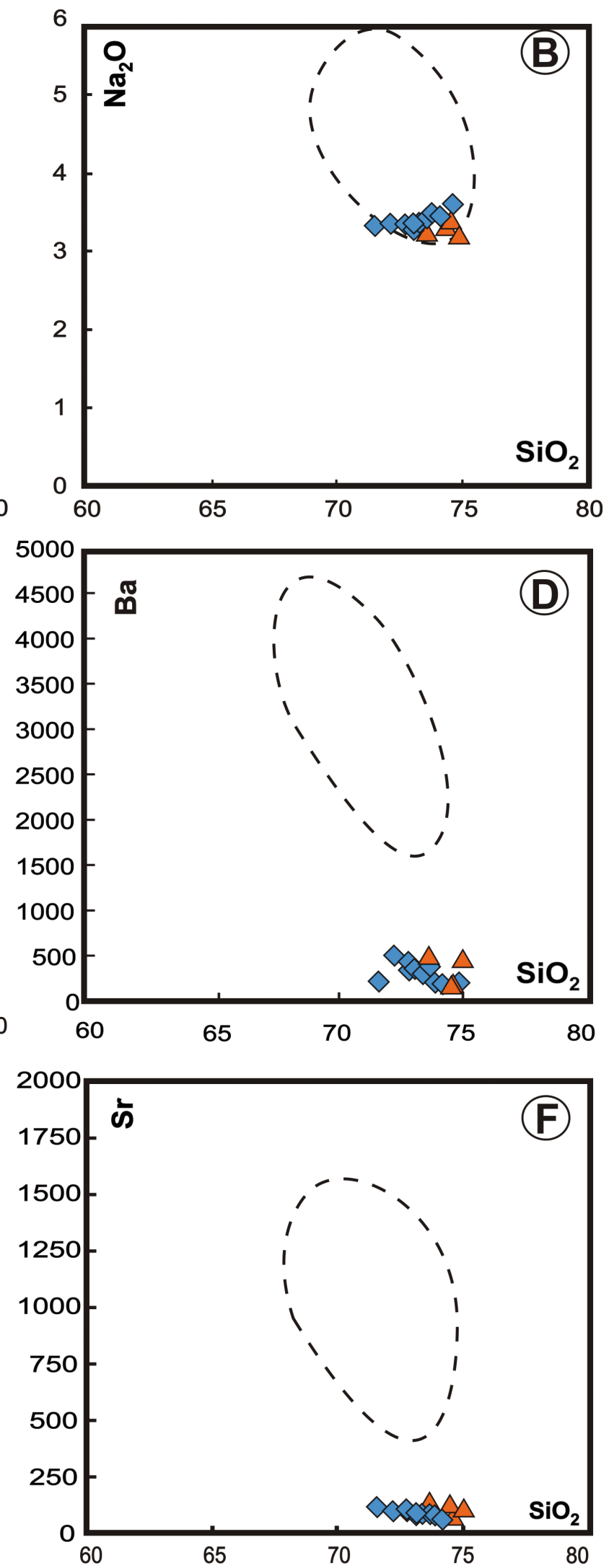

Figura 14. Diagramas binários de variação para elementos maiores e menores com os campos dos granitos alcalinos (polígonos tracejados) segundo Nascimento et. al. (2015) e plote das amostras do Stock Flores. A) $\mathrm{SiO}_{2}$ versus $\mathrm{Al}_{2} \mathrm{O}_{3} ; \mathrm{B}_{\text {) } \mathrm{SiO}_{2} \text { versus Na}} \mathrm{O}$; C) $\mathrm{SiO}_{2}$ versus $\mathrm{K}_{2} \mathrm{O}$; D) $\mathrm{SiO}_{2}$ versus $\mathrm{Ba}$; E) $\mathrm{SiO}_{2}$ versus $\mathrm{Rb}$; F) $\mathrm{SiO}_{2}$ versus $\mathrm{Sr}$.

Figure 14. Diagrams of binary variation for major and minor elements with fields of alkaline granites (dashed polygons) according Nascimento et al. (2015) and plot of samples of the Flores Stock. A) $\mathrm{SiO}_{2}$ versus $\mathrm{Al}_{2} \mathrm{O}_{3} ; \mathrm{B}$ ) $\mathrm{SiO}_{2}$ versus $\mathrm{Na}_{2} \mathrm{O} ; \mathrm{C}$ ) $\mathrm{SiO}_{2}$ versus $\mathrm{K}_{2} \mathrm{O} ; \mathrm{D}$ ) $\mathrm{SiO}_{2}$ versus $\mathrm{Ba}$; E) $\mathrm{SiO}_{2}$ versus $\mathrm{Rb}$; F) $\mathrm{SiO}_{2}$ versus $\mathrm{Sr}$. 
Apesar do caráter evoluído das rochas do Stock Flores $\left(\mathrm{SiO}_{2} \geq 71 \%\right)$, o que usualmente dificulta uma melhor definição da filiação magmática de tais rochas, os dados geoquímicos apresentados mostram que as rochas deste granitoide são peraluminosas, com assinatura essencialmente alcalina, em consonância com os dados de química mineral de biotita apresentados por Galindo et al. (2012). Esta assinatura alcalina para o Stock Flores o classifica como um granito tipo-A do subtipo oxidado.

Os parâmetros relativos às condições de cristalização $\left(P, T\right.$ e $\left.\mathrm{fO}_{2}\right)$ do magma que deu origem ao Stock Flores, equacionados a partir de dados mineralógicos e químicos, indicam temperatura liquidus da ordem de $800^{\circ} \mathrm{C}$ (geotermômetros de apatita e zircão), e solidus em torno de $680^{\circ} \mathrm{C}$ (geotermômetro do sistema Qz-Ab-Or). A fugacidade de oxigênio moderada a elevada foi estabelecida com base em dados mineralógicos petrográficos, normativo-CIPW, e a partir de química mineral de biotita.

A partir da temperatura indicada para o liquidus $\left(800^{\circ} \mathrm{C}\right)$, associadas com os dados de geocronológicos de ${ }^{40} \mathrm{Ar} /{ }^{39} \mathrm{Ar}$ em biotita de $504 \pm 4 \mathrm{Ma}$ (Morais Neto, 2009) e U-Pb em zircões de $553 \pm 4$ Ma (Souza et al., 2015), foi possível calcular a taxa de resfriamento do Stock Flores. Considerando que a temperatura de fechamento da biotita é em torno de $300^{\circ} \mathrm{C}$ e a do zircão é em torno de $800^{\circ} \mathrm{C}$ tem-se, assim um período de 50 Ma para resfriar $500^{\circ} \mathrm{C}$, o que resulta em uma taxa de resfriamento linear de $10^{\circ} \mathrm{C} / \mathrm{Ma}$.

Com base nas pressões de 3,0 e 5,0 kbars, estimadas a partir do sistema Qz-Ab-Or, e uma densidade média de $2,65 \mathrm{Kg} / \mathrm{m}^{3}$ (Maia, 2004), pode-se inferir a partir da equação $\mathrm{P}=\rho \mathrm{g}$ h (Batchelor, 2000) uma profundidade de alojamento do Stock Flores entre 11,6 km e 19,2 km.

Agradecimentos. Este artigo é parte da dissertação de mestrado da primeira autora, junto ao Programa de Pós-graduação em Geodinâmica e Geofísica da Universidade Federal do Rio Grande do Norte que agradece à CAPES pela concessão de bolsa de estudos.

\section{Referências}

Almeida, F.F.M., Hasuy, Y., Brito Neves, B.B. \& Fuck, R.A. 1977. Províncias estruturais brasileiras. In: SIMPÓSIO DE GEOLOGIA DO NORDESTE, 8., 1877, Campina Grande. Atas... Campina Grande, SBG, v.6, p.363-391.

Almeida, F.F.M., Brito Neves B.B. \& Fuck R.A. 1981. Brazilian structural provinces: an introduction. EarthScience Reviews, 17: 1-29.

Almeida, A.F.M., Leonardos, O.H. \& Valença, J. 1967. Re- view on granitic rocks of Northeast South America. In: INTERTIONAL UNITION GEOLOGICAL SCIENCIES SYMPOSIUM, 1., 1967, Recife. Atas... Recife, UNESCO, v. 1, p. 41.

Barbarin, B. 2005. Mafic magmatic enclaves and mafic rocks associated with some granitoids of the central Sierra Nevada batholith, California: nature, origin and relations with the hosts. Lithos, 80: 155-177.

Barbey, P. 2009. Layering and schlieren in granitoids: A record of interactions between magma emplacement, crystallization and deformation in growing plutons. Geologica Belgica, 12: 109-133.

Barrière, M. 1976. Flowage differentiation: limitation of the "Bagnold effect" to narrow intrusions. Contribution to Mineralogy and Petrology, 55: 139-145.

Barrière, M. 1981. On curved laminae, graded layers, convection currents and dynamic crystal sorting in the Ploumanac'h (Brittany) subalkaline granite. Contributions to Mineralogy and Petrology, 77: 217-224.

Blundy, J. \& Cashman, K. V. 2001. Ascent-driven crystallisation of dacite magmas at Mount St. Helens, 1980-1986. Contributions to Mineralogy and Petrology, 140: 631-650.

Blundy, J.D. \& Holland, T.J.B. 1990. Calcic amphibole equilibria and a new amphibole-plagioclase geothermometer. Contributions Mineral and Petrology, 104: 208-224.

Bowen, N.L. 1915. The later stages of the evolution of the igneous rocks. Journal of Geology, 23: 1-89.

Brito Neves, B.B. \& Pessoa, R.J.R. 1974. Considerações sobre as rochas graníticas do nordeste oriental. In: CONGRESSO BRASILEIRO DE GEOLOGIA, 28., 1974 Porto Alegre, Anais... Porto Alegre, SBG, v. 4, p. 143157.

Brito Neves, B.B., Van Schmus, W.R., Santos, E.J., Campos Neto, M.C. \& Kozuch, M. 1995. O evento Cariris Velhos na Província Borborema. Revista Brasileira de Geociências, 25(4): 279-296.

Campbell, I.H., Griffiths, R.W.\& Hill, R.I. 1989. Melting in an Archaean mantle plume: Head it's basalts, tail it's komatiites. Nature, 339: 697-699.

Cavalcante, R. Galindo, A.C., Silva, F.C.A. \& Souza, R.F. 2014. Química mineral e condições de cristalização do Plúton Granítico Barcelona, extremo nordeste da Província Borborema, Nordeste do Brasil. Pesquisas em Geociências, 41(3): 257-272.

Clemens, J.D., Holloway, J.R. \& White, A.J.R. 1986. Origin of an A-type granite: experimental constraints. American Mineralogist, 71: 371-324.

Collins, W.J., Beams, D.,White, J.R., Chappell \& B.W. 1982. Nature and origin of A-type granites with particular reference to south-eastern Australia. Contributions to Mineralogy and Petrology, 80: 189-200.

Costi, H.T., Dall'Agnol, R., Borges, R.M.K., Minuzzi, O.R.R. \& Teixeira, J.T. 2002. Tin-bearing sodic episyenites associated with the Proterozoic, A-Type Água Boa Granite, Pitinga Mine, Amazonian Craton, Brazil. Gondwana Research, 5: 435-451.

Dall'Agnol, R. \& Oliveira, D.C. 2007. Oxidized, magnetite-series, rapakivi-type granites of Carajás, Brazil: implications for classification and petrogenesis of 
A-type granites. Lithos 93: 215-233.

De La Roche, H., Leterrier, J., Granclaude, P. \& Marchal, M. 1980. A classification of volcanic and plutonic rocks using R1-R2 diagram and major element analyses. Its relationship with current nomenclature. Chemical Geology, 29: 183-210.

Delgado, I.M., Souza, J.D., Silva, L.C., Silveira Filho, N.C., Santos, R.A., Pedreira, A.J., Guimarães, J.T., Angelim, L.A.A., Vasconcelos, A.M., Gomes, I.P., Lacerda Filho, J.V., Valente, C.R., Perrotta, M.M. \& Heineck C.A. 2003. Geotectônica do Escudo Atlântico. In: Bizzi, L.A. (Ed). Geologia, Tectônica e Recursos Minerais do Brasil: Texto, mapas e SIG. Brasília, CPRM, p. 227-234.

Didier, J. * Barbarin, B. (Eds.), 1991. Enclaves and Granite Petrology, Developments in Petrology. Vol. 13, Amsterdam, Elsevier, 625p.

Evensen, N.H., Hamilton, P.J. \& O’Nions, R.K. 1978. Rare earth abundances in condritic meteorite. Geochimica et Cosmochimica, 42 (8): 1199-1212.

Farner, M.J. \& Lee, C. T. A. 2013. A late-stage origin for schlieren in felsic plutons. GSA Abstracts, 45: 7.

Figueiredo, M., 1985. Introdução à geoquímica dos Elementos Terras Raras. Boletim IG-USP, 16: 15-31.

Frost, B.R., Barnes, C.G., Collins, W.J., Arculus, R.J., Ellis, D.J. \& Frost, C.D. 2001. A geochemical classification for granitic rocks. Journal of Petrology, 42: 20332048.

Galindo, A.C. 1993. Petrologia dos granitóides brasilianos da região de Caraúbas-Umarizal, oeste do Rio Grande do Norte. Belém, 370p. Tese de Doutorado, Programa de Pós graduação em Geologia e Geoquímica, Centro de Geociências, Universidade do Pará.

Galindo, A.C., Dall'Agnol, R., McReath, I., Lafon, J.M. \& Teixeira, N. 1995. Evolution of Brasiliano age granitoid types in a shear-zone environment, Umarizal-Caraúbas region, Rio Grande do Norte, northeast Brazil. Journal of South American Earth Sciences, 8: 79-95.

Galindo, A.C., Dall'Agnol, R., Mcreath, I., Leterrier, J. \& Nascimento, M.A.L. 1997a. Granitóide Quixaba: um magmatismo monzonítico (shoshonítico?) no extremo oeste da Faixa Seridó. In: SIMPÓSIO DE GEOLOGIA DO NORDESTE, 15., 1997, Fortaleza. Atas... Fortaleza, SBG, v. 1, p. 268-272.

Galindo, A.C., Jardim de Sá, E.F., Nascimento, R.S.C., Hollanda, M.H.B.M., Nascimento, M.A.L. \& Lardeaux, J.M. 1997b. Caracterização geoquímica e contexto geodinâmico dos granitóides alcalinos na porção oriental da Faixa Seridó (RN-PB). In: SIMPÓSIO DE GEOLOGIA DO NORDESTE, 15., 1997, Fortaleza, Atas... Fortaleza, SBG, v.1, p. 263-267.

Galindo, A.C., Silva, F.C.A. \& Souza, Z.S. 2012. Química Mineral de leucomicrogranitos Neoproterozoicos do Domínio Rio Grande do Norte. Geochimica Brasiliensis, 26: 19-28.

Griffiths, R.W. 1986. Thermals in extremely viscous fluids, including the effects of temperature-dependent viscosity. Journal of Fluid Mechanics, 166: 115-138.

Harris, N.B.W., Pearce, J.A. \& Tindle, A.G. 1986. Geochemical characteristics of collision-zone magmatism. In: Coward, M. P., Ries, A. C. (Eds.). Collision tectonics. Geological Society Special Publication, 19: 67-
81.

Hibbard, M.J. 1995. Petrography to Petrogenesis. New Jersey, Prentice Hall, p. 587.

Hollanda, M.H.B.M. 1998. Mecanismos de alojamentos de magmas granitóides: exemplo do Plúton de Japi (RN). Natal, 126p. Dissertação de Mestrado. Programa de Pós-Graduação em Geodinâmica e Geofísica, Centro de Ciências Exatas e da Terra, Universidade Federal do Rio Grande do Norte.

Hollanda, M.H.B.M., Sá, E.F.J., Galindo, A.C. \& Souza, Z.S. 1999. Shear zone control on the emplacement of granitoid magmas: an example from Japi Complex, Seridó Belt, NE-Brazil. Revista Brasileira de Geociências, 29(1): 41-46.

Irvine, T.N. 1980. Magmatic density currents and cumulus processes. American Journal of Science, 280-A: $1-58$

Jardim de Sá, E. F. 1984. Geologia da região do Seridó: reavaliação de dados. In: SIMPÓSIO DE GEOLOGIA DO NORDESTE, 11., Natal, Resumo Expandido... Natal, SBG, v. 2, p. 143-144.

Jardim de Sá, E.F.1994. A Faixa Seridó (Província Borborema, NE do Brasil) e o seu significado geodinâmico na cadeia Brasiliana/Pan-Africana. Brasília, 803p. Tese de Doutorado, Programa de Pós-graduação em Geologia, Universidade de Brasília.

Jardim de Sá, E.F. \& Salim, J. 1980. Reavaliação dos conceitos estratigráficos na região do Seridó (RN-PB). Mineração e Metalurgia, 80: 16-28.

Jardim de Sá, E.F., Legrand, J.M. \& Mcreath, I. 1981. "Estratigrafia" de rochas granitóides na região do Seridó (RN-PB) com base em critérios estruturais. Revista Brasileira de Geociências, 11: 50-57.

Kaur, P., Chaudhri N., Hofmann, A.W., Raczek, I., Okrusch, M., Skora, S. \& Baumgartner, L.P. 2012. Two-stage, extreme albitization of A-type granites from Rajasthan, NW India. Journal of Petrology, 53: 919-948.

Lameyre, J. 1987. Granites and evolution of the crust. Revista Brasileira de Geociências, 17(4): 349-359.

Le Maitre, R.W. 2002. Igneous Rocks: a classification and glossary of terms. Cambridge, University Press, 236p.

Loiselle, M.C. \& Wones, D.R. 1979. Characteristics and origin of anorogenic granites. Geological Society of America, 11: 468.

Luth, W.C., Jahns, R.H. \& Tuttle, O.F. 1964. The granite system at pressures of 4 to 10 kilobars. Journal of Geophysical Research, 69(4): 759-773.

Maia, S.M.C. 2004. Estudo integrado geológico-tecnológico de rochas ornamentais: os granitos Flores e Jacarandá, RN. Natal, 75p. Dissertação de Mestrado. Programa de Pós-Graduação em Geodinâmica e Geofísica, Centro de Ciências Exatas e da Terra, Universidade Federal do Rio Grande do Norte.

Maniar, P.D. \& Piccoli P.M. 1989. Tectonic discrimination of granitoids. Geological Society of America Bulletin, 101: 635-643.

Mariano, G. \& Sial, A.N. 1990. Coexistence and mixing of magmas in the late precambrian Itaporanga batholith, state of Paraíba, northeastern Brazil. Revista Brasileira de Geociências, 20(11): 101-110.

Miyashiro, A., 1978. Nature of alkalic volcanic rock se- 
ries. Contributions to Mineralogy and Petrology, 66: 91-104.

Morais Neto, J.M. 2009. Thermochronology, lanscape evolution and denudational history of the eastern Borborema Province, northeastern Brazil. PhD Thesis, School of Earth Sciences. University of Queensland.

Nardi, L.V.S. \& Bitencourt, M.F. 2009. A-type granitic rocks in post-collisional settings in southernmost Brazil: their classification and relationship with tectonics and magmatic series. Canadian Mineralogist, 47(60): 1493-1503.

Nascimento, R.S.C. 1998. Petrologia dos Granitóides Brasilianos associados a Zona de Cisalhamento Remígio-Pocinhos (PB). Natal, 133p. Dissertação de Mestrado, Programa de Pesquisa e Pós-Graduação em Geodinâmica e Geofísica, Centro de Ciências Exatas, Universidade Federal do Rio Grande do Norte.

Nascimento, M.A.L., Antunes, A.F., Galindo, A.C., Jardim de Sá, E.F. \& Souza, Z.S. 2000. Geochemical signatures of the Brasiliano-age plutonism in the Seridó belt, Northeastern Borborema Province (NE Brazil). Revista Brasileira de. Geociências, 30: 161-164.

Nascimento, M.A.L., Medeiros, V.C. \& Galindo, A.C. 2008. Magmatismo Ediacarano a Cambriano no Domínio Rio Grande do Norte, Província Borborema, NE do Brasil. Estudos Geológicos, 18: 4-29.

Nascimento, M.A.L., Galindo, A.C. \& Medeiros, V.C. 2015. Ediacaran to Cambrian magmatic suites in the Rio Grande do Norte domain, extreme Northeastern Borborema Province (NE of Brazil): Current knowledge. Journal of South American Earth Science, 58: 281-299.

Nascimento, R.S.C. 1998. Petrologia dos Granitóides Brasilianos associados a Zona de Cisalhamento Remígio-Pocinhos (PB). Natal, 133p. Dissertação de Mestrado, Programa de Pesquisa e Pós-Graduação em Geodinâmica e Geofísica, Centro de Ciências Exatas, Universidade Federal do Rio Grande do Norte.

Pearce, J.A. 1996. Sources and settings of granitic rocks. Episodes, 19: 120-125.

Pearce, J.A., Harris, N.B.W. \& Tindle, A.G. 1984. Trace elements discrimination diagrams for the tectonic interpretation of granitic rocks. Journal of Petrology, 25(4): 956-983.

Pitcher, W.S. 1983. Granites: typology, geologic environment and melting relationships. In: Atherton, M.P. \& Gribble, C.D. (Ed). Migmatites. Melting and Metamorphism. Nantwich, Shiva, p. 277-285.

Rogers, J.J.W. \& Greenberg, J.K. 1981. Trace elements in continental margin magmatism. Part III. Alkali granites and their relationship to cratonization. Bulletin Geological Society of America, 92: 6-9.

Santos, E.J. 1996. Ensaio preliminar sobre terrenos e tectônica acrescionária na Província Borborema. In: CONGRESSO BRASILEIRO DE GEOLOGIA, 39., 1996, Salvador. Atas... Salvador, SBG, v. 7, p. 47-50.

Santos, E.J. 1999. Belém do São Francisco, folha SC.24X-A: Estados de Pernambuco, Alagoas e Bahia. Programa de Levantamentos Geológicos do Brasil. Brasília: CPRM. CD-ROM.
Santos, E.J. \& Medeiros V.C. 1999. Constraints from granitic plutonism on proterozoic crustal growth of the Transverse Zone, Borborema Province, NE-Brazil. Revista Brasileira de Geociências, 29: 73-84.

Santos, E.J. dos, \& Melo, C.B.M. 1978. Diversidade do plutonismo granítico do nordeste. In: CONGRESSO BRASILEIRO DE GEOLOGIA, 30., 1978, Recife. Anais... Recife, SBG, v.6, p. 2624-2634.

Santos, E.J., Brito Neves, B.B., Van Schmus, W.R., Oliveira, R.G. \& Medeiros, V.C. 2000. An overall view on the displaced terrane arrangement of the Borborema Province, NE Brazil. In: INTERNATIONAL GEOLOGICAL CONGRESS, 31., 2000, Rio de Janeiro, Anais... Rio de Janeiro, SBG, 1 CD-ROM.

Scaillet, B. \& Pichavant, M. 1999. An experimental study of a lower proterozoic A-type granite from the eastern Amazonian Craton, Brazil. Journal of Petrology, 40(11): 1673-1698.

Schmidt, M.W. 1992. Amphibole composition in tonalite as a function of pressure: an experimental calibration of the Al-in-hornblende barometer. Contributions Mineral and Petrology, 110: 304-310.

Sial, A.N. 1987. Granitic rocks in northeast Brazil. In: INTERNATIONAL SYMPOSIUM ON GRANITES AND ASSOCIATED MINERALIZATIONS, 1., 1987, Salvador, Anais... Salvador, SGRN, v. 1, p. 61-69.

Smith, T.E. 1975. Layered granitic rocks at Chebutco Head, Halifax County, Nova Scotia. Canadian Journal of Earth Sciences, 12: 456-463.

Souza, Z.S., Martin, H., Peucat, J., Jardim de Sá, E.F. \& Macedo, M.H.F. 2007. Calc-Alkaline Magmatism at the Archean-Proterozoic Transition: the Caicó Complex Basement (NE Brazil). Journal of Petrology, 48: 2149-2185.

Souza, Z.S., Kalsbeek, F., Xiaodong, D., Li, J.W., Frei, R., Kokfelt, T.F., Dantas, E.L., Jianwei, l., Pimentel, M.M. \& Galindo, A.C. 2015. Generation of continental crust in the northern part of the Borborema Province, northeastern Brazil, from Archaean to Neoproterozoic. Journal of South American Earth Sciences, 1: 1-29.

Streckeisen, A.L. 1976. To each plutonic rock it's a proper name. Earth Science Reviews, 12: 1-33.

Sylvester, P.J. 1989. Post-collisional alkaline granites. Journal of Geology, 97: 261-280.

Thompson, R.N. 1982. Magmatism of the British tertiary volcanic province. Scott. Journal Geology, 18: 49107.

Tuttle, O. F. \& Bowen, N. L. 1958. Origin of granite in the light of experimental studies in system NaAlSi308 KalSi308 - SiO2 - H20. Geological Society of America Memoirs, 74: 153.

Van Schmus, W.R., Brito Neves, B.B., Hackspacher, P.C. \& Babinski, M. 1995. U-Pb and Sm-Nd geochronological studies of the Eastern Borborema Province, Northeastern Brazil, initial conclusions. Journal of South American Earth Sciences, 8(3-4): 267-288.

Vernon, R.H. 1990. Crystallization and hybridism in microgranitoid enclave magmas: microstructural evidence. Journal of Geophysical Research, 95: 1784917859. 
Vernon, R.H. 2004. A Practical Guide to Rock Microstructure. Cambridge, University Press, p. 594.

Watson, E.B. \& Harrison, T.M. 1983. Zircon saturation revisited: temperature and composition effects in a variety of crustal magma types. Earth and Planetary Science Letters, 64: 295-304.

Watson, E.B. \& Harrison, T.M. 1984. Acessory minerals and the geochemical evolution of crustal magmatic system: a summary and prospectus of experimental approaches. Physics of the Earth and Planetary Interiors, 35: 19-30.

Weinberg, R.F., Sial, A.N. \& Pessoa, R.R. 2001. Magma flow within the Tavares pluton, northeastern Brazil: compositional and thermal convection. Geological Society of America Bulletin, 113: 508-520.

Wilson, J. T. 1963. A possible origin of the Hawaiian Islands. Canadian Journal of Physics, 41: 863-870.

Manuscrito 607

Editores: Lauro V. S. Nardi \& Paulo A. Souza
Winter, J.D. 2001. Principles of Igneous and Metamorphic Petrology. New Jersey, Prentice Hall, 697p.

Wones, D. R. 1989. Significance of the assemblage titanite + magnetite + quartz in granitic rocks. American Mineralogist, 74: 744-749.

Wright, J.B. 1969. A simple alkalinity ratio and its application to questions of non-orogenic granite genesis. Geological Magazine, 106: 370-384.

Yuguchi, T. \& Nishiyama, T. 2007. Cooling process of a granitic body deduced from the extents of exsolution and deuteric sub-solidus reactions: Case study of the Okueyama granitic body, Kyushu, Japan. Lithos, 97: 395-421.

Zorpi, M.J., Coulon, C., Orsini, J.B. \& Cocirta, C. 1989. Magma mingling, zoning and emplacement in calc-alkaline granitoid plutons. Tectonophysics, 157: 315-329. 